Fernando Silvério Ribeiro

\title{
Pressão de propágulos ou distúrbios? Decifrando os determinantes da invasão por cachorros na Mata Atlântica
}

Disturbance or propagule pressure? Unraveling the drivers of the invasion by free-ranging dogs in Atlantic forest

São Paulo, 2016 


\author{
Universidade de São Paulo \\ Instituto de Biociências \\ Programa de Pós-Graduação em Ecologia
}

\title{
Pressão de propágulos ou distúrbios? Decifrando os determinantes da invasão por cachorros na Mata Atlântica
}

\author{
Disturbance or propagule pressure? Unraveling the drivers of the \\ invasion by free-ranging dogs in Atlantic forest
}

Fernando Silvério Ribeiro

\author{
Dissertação apresentada ao Instituto de \\ Biociências da Universidade de São Paulo \\ para obtenção de Título de Mestre em \\ Ciências, na área de Ecologia. \\ Orientadora: \\ Prof $^{a}$. Dr ${ }^{a}$. Renata Pardini
}

São Paulo, 2016 


\section{Ficha Catalográfica}

\begin{tabular}{|} 
Ribeiro, Fernando Silvério \\
Pressão de propágulos ou distúrbios? Decifrando os \\
determinantes da invasão por cachorros na Mata Atlântica \\
Disturbance or propagule pressure? Unraveling the \\
drivers of the invasion by free-ranging dogs in Atlantic forest \\
45 p. \\
Dissertação (Mestrado) - Instituto de Biociências da \\
Universidade de São Paulo. \\
1. Canis lupus familiaris 2. invasão biológica 3. espécie \\
exótica 4. perda de habitat 5. estrutura da paisagem 6. \\
densidade populacional I. Universidade de São Paulo. Instituto \\
de Biociências.
\end{tabular}

\section{Comissão Julgadora:}

$\operatorname{Prof}(\mathrm{a}) . \operatorname{Dr}(\mathrm{a})$.

$\operatorname{Prof}(\mathrm{a}) . \operatorname{Dr}(\mathrm{a})$.

Profa. Dra. Renata Pardini

Orientadora 


\section{AGRADECIMENTOS}

Agradeço a:

FAPESP, pelo financiamento do Projeto Temático Interface (2013/23457-6), ao qual este trabalho é vinculado e à CAPES, pela bolsa de mestrado concedida.

Renata Pardini, minha orientadora, pela imensa dedicação a este trabalho, aos seus alunos e à ciência. Muito obrigado pelos ensinamentos, conselhos e paciência com os deslizes. E também pela amizade e companhia fora do mundo acadêmico. É um prazer ser seu aluno e amigo. Valeu, Rê!

Jean Paul Metzger, por coordenar o Projeto Temático Interface e possibilitar a realização desse trabalho.

Instituto de Biociências da USP e Departamentos de Ecologia e Zoologia, pela infraestrutura concedida desde o começo de minha graduação e durante todo o mestrado.

Aos membros do comitê, Elizabeth Nichols e Ronaldo Gonçalves Morato, pela disponibilidade em ajudar, inclusive no trabalho de campo, e pelos valiosos conselhos que melhoraram a qualidade deste trabalho.

Ao pessoal do Lepac, especialmente todos que participaram do mapeamento das paisagens, especialmente Larissa Boesing, Elizabeth Nichols e Francisco d'Albertas Gomes de Carvalho, e a Isabella Romitelli pela disponibilidade e paciência para lidar com a prestação de contas.

Aos colegas do DICOM, por toda a ajuda em campo, com as disciplinas, com o R e pelas discussões nos seminários do laboratório.

A todos os muitos companheiros de campo, desde os primeiros passos de reconhecimento das paisagens, conversas com proprietários, aberturas de trilhas, projeto piloto e, 
finalmente, a coleta de dados. Especialmente a família Casa das Vespas e suas subequipes, cachorrada (Elvira, Lucas e Vini), rola-bosta (Vivi, Bruna, Liz e Gabriel) e passarinhos (Lari, Paulinho e André). Muito obrigado por fazerem do campo um período inesquecível! A todos os proprietários e moradores das áreas de estudo, que permitiram o acesso às áreas de estudo e pela disponibilidade de responderem as entrevistas.

Aos vizinhos de Joanópolis e Nazaré, seu Persival, dona Maria, dona Esmeralda, Elmo e seu Brasilino, pela hospedagem, amizade e disponibilidade em ajudar a resolver qualquer problema.

E, por fim, a minha família, pelo suporte e apoio incondicional. 


\section{ÍNDICE}

1. RESUMO

2. ABSTRACT 2

3. INTRODUÇÃO 3

4. MATERIAL E MÉTODOS

$\begin{array}{ll}\text { 4.1. Área de estudo } & 7\end{array}$

4.2. Delineamento amostral

$\begin{array}{lr}\text { 4.3. Coleta de dados } & 10\end{array}$

$\begin{array}{ll}\text { 4.3.1. Cachorros em fragmentos florestais } & 10\end{array}$

$\begin{array}{ll}\text { 4.3.2. Pressão de propágulos } & 12\end{array}$

4.3.3. Distúrbios associados à perda de habitat na escala da paisagem $\quad 13$

$\begin{array}{ll}\text { 4.4. Análise de dados } & 15\end{array}$

$\begin{array}{ll}\text { 4.4.1. Modelos de abundância } & 15\end{array}$

4.4.2. Tipos de distribuição de abundância e sessões de amostragem 16

$\begin{array}{ll}\text { 5. RESULTADOS } & 17\end{array}$

$\begin{array}{ll}\text { 6. DISCUSSÃO } & 22\end{array}$

\begin{tabular}{l|} 
6.1. Implicações para a conservação \\
\hline
\end{tabular}

$\begin{array}{ll}\text { 7. CONCLUSÃO } & 29\end{array}$

8. REFERÊNCIAS BIBLIOGRÁFICAS 31

$\begin{array}{ll}\text { 9. ANEXOS } & 39\end{array}$ 


\section{RESUMO}

Invasões biológicas representam atualmente a segunda maior ameaça à biodiversidade e dois fatores são considerados os mais importantes para o sucesso de invasões: pressão de propágulos e distúrbios. Um tipo de distúrbio antrópico que pode promover invasões, por mudar a quantidade de habitats alterados e a extensão de bordas entre eles e habitats nativos, é a perda de habitat. Apesar da reconhecida importância da pressão de propágulos e dos distúrbios, poucos estudos os investigaram simultaneamente e, os que o fizeram, apresentam limitações, como escalas espaciais pequenas e correlações entre os determinantes, dificultando a compreensão da importância relativa e interações entre eles. Cachorros são os carnívoros mais abundantes no mundo. Em áreas rurais, a maioria mantém comportamento de animal de vida de livre, interagindo com e afetando espécies nativas através de predação, transmissão de doenças e competição. Usando um banco de dados obtido através de armadilhas fotográficas e censo da população de cachorros em uma região de Mata Atlântica de 300,000 ha, avaliamos a importância relativa e interações entre pressão de propágulos e distúrbios para a invasão por cachorros. Selecionamos 12 paisagens de 2830 ha cada, variando de 10 a 50\% de floresta nativa remanescente. Em cada uma, alocamos através de amostragem aleatória estratificada 8 pontos de amostragem em florestas nativas, onde uma armadilha fotográfica foi instalada por $\sim 42$ dias consecutivos. Todos os domicílios em cada paisagem foram visitados para a contagem do número de cachorros. A pressão de propágulos foi quantificada como a densidade de cachorros criados e a média e mediana das distâncias entre os locais de criação e a floresta nativa mais próxima; e distúrbios, como a proporção da paisagem ocupada por floresta nativa e total (nativa e exótica) e a extensão de bordas entre florestas nativas e áreas abertas. Através da identificação de cachorros nas fotos e considerando cada paisagem como uma unidade amostral, nós comparamos por AICc modelos de abundância ( $N$-mixture) para estimar a abundância de cachorros em florestas nativas, considerando a detecção imperfeita. $O$ único modelo selecionado indica que a abundância de cachorros em florestas nativas é maior onde a densidade de cachorros é mais alta e a cobertura florestal total é menor $(\omega \mathrm{i}=0.82)$. A densidade de cachorros criados foi mais importante que a distribuição espacial dos indivíduos, e a cobertura floresta total mais importante que a extensão de bordas, para a abundância de cachorros invasores. A abundância estimada de cachorros variou de 12 a 79 (30.9 \pm 19.5$)$, e a proporção de cachorros criados que invadem florestas de a 6 a $21 \%$ (12 $\pm 6 \%$ ), entre as paisagens. Nossos resultados indicam que a perda de habitat é tão importante quanto a pressão de propágulos para a invasão de florestas nativas por cachorros, mas seus efeitos são aditivos em vez de sinérgicos. Dado que cachorros frequentemente realizam movimentos longos em áreas abertas, nós levantamos a hipótese de que a capacidade de deslocamento é a causa do efeito desprezível da distribuição espacial dos indivíduos criados sobre a invasão, e que florestas representam barreiras a estes movimentos, tornando o efeito da cobertura florestal mais importante do que o efeito da extensão de bordas (mais relacionada a extensão de acesso a floresta). Além disso, o número e proporção de cachorros invasores são expressivos, colocando o cachorro na posição de carnívoro mais abundante em remanescentes florestais. Junto com os conhecidos impactos severos de cachorros sobre espécies nativas, estes números sugerem a urgência de planos de ação para controlar a invasão por cachorros. Além dos métodos tradicionais de controle populacional, o contexto da paisagem deve ser levado em conta nestes planos. Paisagens muito desmatadas devem ser priorizadas, e manter e restaurar florestas também devem ser valorizados pelos efeitos negativos sobre invasões biológicas. Por fim, dada a associação da invasão por cachorros com a perda de habitat e com a densidade de cachorros e da população humana, sugerimos que pelo menos parte dos efeitos negativos sobre mamíferos nativos usualmente atribuídos ao desmatamento e a caça podem ser causados pela invasão por cachorros. 


\section{ABSTRACT}

Biological invasions are currently the second main threat to biodiversity and two drivers are considered as the most important for invasions success: propagule pressure and disturbance. An anthropogenic disturbance that can promote invasions, by changing the amount of altered habitats and the extension of edges between altered and native habitats, is habitat loss. Despite the recognized importance of propagule pressure and disturbance, few studies have simultaneously investigated these factors, and those that did so present limitations, such as small spatial scales and correlations between drivers, impairing our understanding of the relative importance and interactions between these drivers. Dogs are the most abundant carnivores worldwide; in rural areas, most are free ranging, interacting and affecting native species through predation, disease transmission and competition. Using a camera trap dataset and censuses of dog populations obtained across a 300,000-ha Atlantic forest region, we evaluated the relative importance and interactions of propagule pressure and disturbance as drivers of dog invasion. We selected 12 2830-ha landscapes, ranging from 10 to 50\% remaining native forest. Within each, we selected through a random-stratified sample 8 forest sites where a camera trap was set for $\sim 42$ consecutive days. All households in each landscape were visited to count the number of dogs. Propagule pressure was quantified as the density of raised dogs, and mean and median distances between locations where dogs were raised and the nearest forest; and disturbance as the proportion of the landscape occupied by native forest and by total forest (native and exotic), and edge extension between native forest and open areas. By identifying individual dogs in the photos and considering each landscape as a sampling unit, we compared through AICc N-mixture models to estimate the abundance of dogs within forests, considering imperfect detection. The only selected model indicates that dog abundance in forests is higher where the density of raised dogs is higher and where total forest cover is lower $(\omega \mathrm{i}=0.82)$. Density of raised dogs was more important than the spatial distribution of individuals, and total forest cover more important than edge extension, in determining the abundance of invading dogs. The estimated dog abundance varied from 12 to $79(30.9 \pm 19.5)$, and the proportion of raised dogs that invade forests from 6 to $21 \%(12 \pm 6 \%)$, across landscapes. Our results indicate that habitat loss is as important as propagule pressure in driving the invasion of native forests by dogs, but their effects are additive rather than synergic. Given that dogs frequently make long movements in open areas, we hypothesize that dog vagility is the cause of the negligible effect of spatial distribution of raised individuals on invasion, and that forests represent barriers to these movements, making the effect of forest cover more important than the effect of edge extension (more related to the extension of access to forests). Moreover, the number and proportion of invading dogs are impressive, ranking dogs as the most abundant carnivore in forest remnants. Together with the known severe impacts of dogs on native species, these numbers suggest the urgency of action plans for controlling dog invasion. Beyond the traditional population control, landscape context should be taken into account within strategies to reduce impacts of dogs. Highly-deforested landscapes should be prioritized, and maintaining and restoring forests should be valued also by their negative effects on biological invasions. Finally, given the observed associations between dog invasion and both habitat loss and density of dogs and human populations, we suggest that at least part of the negative effects on native mammals currently attributed to deforestation and hunting can be caused by dog invasion. 


\section{INTRODUÇÃO}

As invasões biológicas são consideradas hoje a segunda, e em alguns grupos a primeira, maior ameaça à extinção de espécies e perda de biodiversidade no mundo (Bailie et al., 2004; Clavero \& García-Berthou, 2005; Bellard et al., 2016a). A expansão e dominância de relativamente poucas espécies através do globo têm se intensificado, acompanhando a crescente circulação de pessoas e produtos pelo planeta (Hulme, 2009), levando ao que muitos têm chamado de uma homogeneização da biota global (Olden et al., 2004). Localmente, invasões biológicas podem afetar todos os níveis de organização dos sistemas ecológicos (Simon \& Townsend, 2003), desde o comportamento de indivíduos até o funcionamento dos ecossistemas (Strayer, 2012), potencialmente alterando serviços ecossistêmicos (Pejchar \& Mooney, 2009) e, nestes casos, interferindo no bem-estar humano.

Dado os inúmeros impactos das invasões biológicas, um esforço grande tem sido colocado na compreensão de suas causas (Lowry et al., 2013). Nos últimos anos, múltiplas hipóteses sobre os determinantes e mecanismos associados a invasões foram propostas, algumas delas focam nas características das espécies que as tornam boas invasoras (Sakai et al., 2001; Kolar \& Lodge, 2001), outras nas características dos ambientes que os tornam mais suscetíveis à invasão (Davis et al., 2000; Shea \& Chesson, 2002) e outras na importância da intensidade e distribuição espacial e temporal dos eventos de introdução, conhecidas como pressão de propágulos, para o sucesso das invasões (Simberloff, 2009). Dado o grande número de casos de invasões de espécies, que ocorrem em uma variedade enorme de circunstâncias específicas, há evidências na literatura de que várias dessas hipóteses possam explicar a invasão em pelo menos algum grau em alguma circunstância (Catford et al., 2009). Ainda assim, algumas hipóteses têm sido rotineiramente corroboradas em diferentes grupos e ambientes, principalmente aquelas relacionadas à pressão de propágulos (Lockwood et al., 2005; Colautti et al., 2006; Simberloff, 2009; Blackburn et al., 2013) e aquelas associadas ao papel dos distúrbios no ambiente (Byers, 2002; Crooks et al., 2011; Jauni et al., 2015; Gantchoff \& Belant, 2015).

A pressão de propágulos relaciona-se com o número de indivíduos da espécie exótica liberados em uma região, e incorpora informações sobre o número total de indivíduos (tamanho do propágulo), número de eventos de introdução (número de propágulos) e os padrões espaciais e temporais da chegada dos propágulos (Simberloff, 2009). Maior pressão de propágulos aumenta as chances do sucesso da invasão, facilitando tanto o estabelecimento da espécie invasora quanto a sua 
expansão, ao aumentar o alcance ou acesso da espécie invasora ao novo habitat (Bossenbroek et al., 2001), diminuir o impacto negativo de processos estocásticos - demográficos, ambientais e genéticos - e do efeito Allee sobre a população de espécie invasora (Blackburn et al., 2015), e/ou aumentar a variabilidade genética e o potencial de adaptação ao novo ambiente (Simberloff, 2009). Nos trabalhos empíricos, frequentemente a pressão de propágulos é inferida indiretamente, através de, por exemplo, registros de tráfego de navios em portos no caso de mexilhões invasores (Simberloff, 2009), ao passo que estimativas diretas são raras e concentramse em trabalhos experimentais (e.g. Hufbauer et al., 2013).

Já os distúrbios são alterações no ambiente decorrentes de ação antrópica ou fenômenos naturais que modificam o habitat rapidamente, em escalas de tempo não compatíveis com as respostas evolutivas das espécies (Byers, 2002). Podem, portanto, facilitar invasões ao criar condições e recursos mais favoráveis a espécies exóticas (Davis et al., 2000) e/ou extinguir ou reduzir populações de espécies nativas, diminuindo os efeitos de interações negativas sobre as espécies invasoras, como competição ou predação (D’Antonio et al., 1999). Um tipo de distúrbio antrópico fortemente associado às invasões biológicas é a conversão de vegetação nativa em outros usos do solo (Didham et al., 2007), um processo que regula a distribuição das espécies nas paisagens por alterar a quantidade de vegetação nativa remanescente (Pardini et al., 2010; Banks-Leite et al., 2012), o tipo e qualidade dos habitats do entorno (Ricketts, 2001; Umetsu et al., 2008) e a extensão de bordas de contato entre vegetação nativa e habitats alterados (Ries et al., 2004). De maneira geral, quanto menor a proporção de vegetação nativa e maior proporção de habitats alterados, e quanto maior a extensão de borda entre eles, maior a área da paisagem com recursos e condições apropriadas para espécies generalistas e invasoras (Umetsu \& Pardini, 2007; Pardini et al., 2010; Estavillo et al., 2013) e maior o acesso dessas espécies ao habitat nativo (Ewers e Didham, 2006). Apesar da reconhecida importância da perda de vegetação nativa e dos diferentes tipos de uso do solo na determinação de invasões biológicas (Vilà e Ibáñez, 2011), ainda são relativamente raros os estudos que quantifiquem esse tipo de distúrbio em escalas espaciais adequadas.

Embora vários trabalhos tenham corroborado a importância tanto da pressão de propágulos como dos distúrbios para o sucesso de invasões biológicas, poucos trabalhos consideram simultaneamente mais de um tipo de determinante das invasões (Lowry et al., 2013). Além disso, entre os trabalhos que analisaram estes dois fatores simultaneamente, a maioria considera distúrbios em escalas locais e/ou de maneira categórica (i.e. presença/ ausência de distúrbio) 
(Britton-Simmons \& Abbott, 2008; Eschtruth \& Battles, 2009; Clark \& Johnston, 2009; Maron et al., 2013), e alguns inferem a pressão de propágulos a partir dos distúrbios (Vilà e Ibañez, 2011). Essas limitações - determinantes considerados isoladamente, quantificados em escalas espaciais pequenas ou de maneira correlacionada - restringem o potencial de entendermos a importância relativa e as possíveis sinergias entre diferentes determinantes nas escalas adequadas, dificultando o delineamento de ações que visem controlar ou impedir invasões. Neste trabalho, pretendemos contribuir com o entendimento da importância relativa e interações entre pressão de propágulos e distúrbios na determinação do sucesso de invasões, abordando esses aspectos na escala de paisagens, e enfocando uma das espécies invasoras mais bem distribuídas no mundo.

O cachorro (Canis lupus familiaris) é atualmente a espécie de carnívoro mais abundante e bem distribuída no planeta. Estimativas recentes apontam para mais de 500 milhões de indivíduos apenas em áreas rurais (Gompper, 2014) e sua distribuição abrange hoje todos os continentes, incluindo ilhas relativamente isoladas. Especialmente em áreas rurais, onde se concentram os remanescentes de vegetação nativa, a maioria dos cachorros são criados soltos, estabelecem área de vida e territorialidade, formam grupos e caçam (Vanak \& Gompper, 2009). Como consequência destes comportamentos de vida livre, são frequentes em áreas de vegetação nativa (Butler et al., 2004; Srbek-Araujo \& Chiarello, 2008; Lacerda et al., 2009; Silva-Rodríguez \& Sieving, 2012; Frigeri et al., 2014; Cassano et al., 2014), onde interagem com as comunidades ecológicas locais. No entanto, ao contrário das espécies nativas, os cachorros têm acesso a uma quantidade atípica de recursos, o que mantém sua densidade populacional muito acima do que se dependessem apenas dos recursos utilizados pelas espécies nativas, e assim podem ser melhor compreendidos como predadores subsidiados pelo homem (Gompper \& Vanak, 2008; Newsome et al., 2015).

O cachorro enquadra-se como espécie invasora considerando qualquer uma das três perspectivas sobre invasões biológicas: a biogeográfica, a ecológica e evolutiva, e a da conservação (Heger et al., 2013). Da perspectiva biogeográfica, uma espécie invasora é a que supera barreiras geográficas que a impediriam de dispersar por novos ambientes. A expansão para novas áreas, que não exerceram pressões evolutivas sobre a espécie, é o foco da perspectiva ecológica e evolutiva. Já a perspectiva da conservação considera uma espécie invasora quando, além de ser introduzida por ação humana, também oferece riscos às espécies nativas. Sabemos que o cachorro teve origem no leste (Pang et al., 2009) ou no oeste asiático e Europa (vonHoldt et al., 2010) e hoje tem distribuição cosmopolita, graças a sua associação com o homem, ocupando, portanto, habitats muito distintos daqueles nos quais evoluiu. Uma grande quantidade de trabalhos tem sugerido 
que os cachorros ameaçam espécies nativas através dos efeitos letais e não-letais da predação (Manor \& Saltz, 2004; Young et al., 2011; Silva-Rodriguez \& Sieving, 2012), competição por exploração ou interferência (Butler \& duToit, 2002; Vanak \& Gompper, 2010) e transmissão de doenças (Woodroffe \& Ginsberg 1999; Cleaveland et al., 2000). De fato, o cachorro hoje é considerado a quarta espécie invasora que mais ameaça vertebrados no mundo (Bellard et al., 2016b), tornando evidente a importância de entendermos os determinantes da intensidade destas invasões em escalas espaciais adequadas para o embasamento de estratégias de manejo.

Neste trabalho, através da amostragem de 12 paisagens (2830 ha cada) distribuídas por uma região de 300.000 ha em um dos hotspots de biodiversidade do Planeta - a Mata Atlântica, pretendemos contribuir para o entendimento dos determinantes da invasão de remanescentes de florestas nativas por cachorros. Através do uso de armadilhas fotográficas instaladas em oito remanescentes de cada uma das paisagens estudadas, que variam de 10 a 50\% de cobertura florestal, e do censo total da população de cachorros em cada uma delas, investigamos a importância relativa e interações entre a pressão de propágulos e distúrbios associados à perda de habitat na escala da paisagem como determinantes da intensidade de invasão. 


\section{MATERIAIS E MÉTODOS}

\section{1. Área de estudo}

O estudo foi realizado em uma área de cerca de 300.000 ha na região Cantareira-Mantiqueira do Planalto Atlântico de São Paulo, Brasil (Figura 1), que engloba as áreas rurais e urbanas de 10 municípios. A região é caracterizada por ondulações e conjuntos de colinas íngremes, com elevação de 700 a 1700 m, previamente cobertas por Mata Atlântica, classificada como floresta ombrófila densa montana. A precipitação média anual é de $1513 \mathrm{~mm}$ e a média das temperaturas mínimas e máximas é de $14,8^{\circ} \mathrm{C}$ e $27,7^{\circ} \mathrm{C}$ na época mais quente (outubro a março) e de $11,3^{\circ} \mathrm{C}$ e $24,6^{\circ} \mathrm{C}$ na época mais fria (abril a setembro) (www.cpa.unicamp.br).

Atualmente, a maior parte das florestas remanescentes está reduzida a fragmentos de diferentes tamanhos e estágios de regeneração. As florestas nativas foram em grande parte substituídas por pastagens e plantações de eucalipto, sendo que outras culturas representam apenas áreas pequenas e intercaladas. Apesar da criação de gado leiteiro ter sido a atividade rural mais

importante da região, recentemente pastagens estão sendo substituídas por plantações de eucalipto, com aumento de até 20 vezes na produção de carvão em alguns municípios da região (www.ibge.com.br).

As áreas rurais da região são densamente povoadas e as paisagens estudadas apresentam em média $154.5 \pm 140.7$ domicílios e, consequentemente, a população de cachorros é bastante alta, com em média $340.17 \pm 140.73$ indivíduos (Anexo 1). Cachorros são criados em $75 \%$ dos domicílios, onde o número de indivíduos varia de 1 a 83 (média $2.78 \pm 3$ ). A maioria dos cachorros é macho (55\%), a idade média é de $4.44 \pm 3.81$ anos (variando de 0 a 20 ) e cerca de $24 \%$ são castrados. Com relação a cuidados veterinários, $65 \%$ tomam banhos regulares, $78 \%$ são vacinados contra a raiva, mas apenas $30 \%$ recebem outras vacinas. O combate a parasitas também não é muito abrangente, sendo que 31\% recebem remédios contra carrapatos e $57 \%$ são tratados com vermífugos. Embora quase a totalidade dos cachorros, mais de 99\%, é alimentada pela menos uma vez ao dia, $15 \%$ buscam alimentos fora de casa, nas áreas de mata, lixeiras ou outras casas. Segundo seus donos, $66 \%$ saem dos arredores do domicílio com frequência e $44 \%$ entram em áreas de vegetação nativa. Dezoito por cento dos cachorros já foram machucados por animais silvestres, $15 \%$ perseguem ou espantam animais silvestres e $7 \%$ já mataram animais silvestres.

A população de cachorros interage com uma comunidade de mamíferos silvestres relativamente simplificada. Como em outras áreas fragmentadas e sujeitas à caça na Mata Atlântica (Chiarello, 
1999; Cullen et al., 2000), não são encontradas na região de estudo algumas espécies de maior porte, como onça-pintada (Panthera onca), anta (Tapirus terrestris) e queixada (Tayassu pecari), enquanto outras, como a onça-parda (Puma concolor) e cateto (Pecari tajacu) são raras. O gambá (Didelphis aurita) é a espécie mais comum e carnívoros de médio porte são relativamente abundantes (Eira barbara, Cerdocyon thous, Nasua nasua e Leopardus spp.).
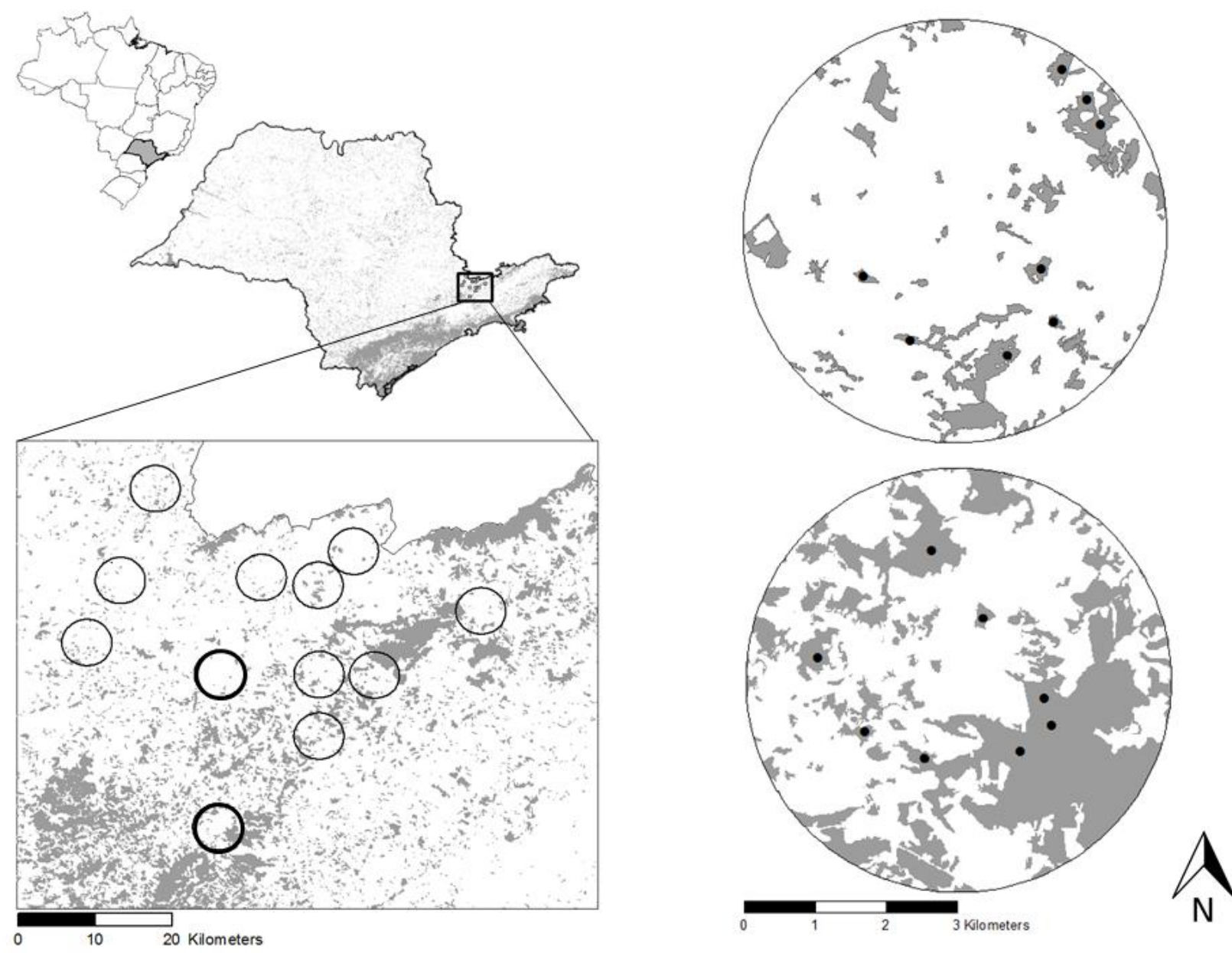

Figura 1: Mapa do Brasil e do estado de São Paulo, com destaque para a área de estudo onde estão representadas as 12 paisagens. Duas delas, uma com baixa e outra com alta proporção de florestas nativas remanescentes, são mostradas em maior detalhe à direita, indicando a localização dos oito pontos de amostragem. Áreas cinza representam os remanescentes de floresta nativa. 


\subsection{Delineamento amostral}

Utilizamos um delineamento amostral hierárquico, selecionando inicialmente 12 paisagens circulares de $3 \mathrm{~km}$ de raio (2830 ha) com diferentes porcentagens de cobertura florestal remanescente, e, dentro de cada uma delas, oito pontos de amostragens em florestas nativas (Figura 1).

Com o intuito de selecionar paisagens que variassem amplamente quanto a cobertura florestal e simultaneamente de controlar quatro potenciais fatores de confusão, utilizamos o método descrito por Pasher et al. (2013). As 12 paisagens foram restritas a altitudes entre 800 e 1200 m, de latossolos férricos vermelhos ou argissolos, onde as áreas desmatadas são ocupadas principalmente por áreas de pastagem. Na medida do possível, evitou-se incluir nas paisagens de estudo grandes rodovias e reservatórios de água, assim como os grandes núcleos urbanos. 0 processo resultou na escolha de 12 paisagens (Figura 1), com variação de 10 a 48\% na proporção de cobertura florestal nativa e de 20 a $67 \%$ na proporção de cobertura florestal total, incluindo florestas nativas e plantadas.

Para garantir que a amostragem dentro de cada paisagem representasse bem a variação na cobertura florestal entre elas, selecionamos os oito pontos de amostragem de cada paisagem (96 pontos no total) através de uma amostragem aleatória estratificada, baseada na proporção da cobertura florestal nativa da paisagem que está contida no maior fragmento de mata nativa. 0 tamanho do maior fragmento em uma paisagem é uma característica importante e que está relacionada à cobertura total do habitat remanescente (Fahrig 2003). Assim, a quantidade de pontos de amostragem alocados aleatoriamente no maior fragmento de cada paisagem foi proporcional à porcentagem de cobertura florestal nativa que este fragmento representa. Os demais pontos de amostragem foram distribuídos aleatoriamente entre os fragmentos de mata nativa restantes maiores que 2,5 ha. Os pontos de amostragem foram restritos a uma distância mínima de $300 \mathrm{~m}$ de outros pontos. Seguindo essas regras e utilizando a ferramenta Sampling Design Tool no ArcGIS v10.1, sorteamos a localização inicial dos pontos de amostragem na faixa de borda entre os fragmentos de mata nativa com áreas de pasto. A partir destes pontos sorteados, estabelecemos os pontos de amostragem no interior dos fragmentos de mata, localizando-os o mais distante possível das bordas, até no máximo $\sim 300 \mathrm{~m}$. Com este procedimento a distância dos pontos de amostragem até a borda mais próxima variou de 14 a $313 \mathrm{~m}$. 


\subsection{Coleta de dados}

\subsubsection{Cachorros em fragmentos florestais}

Instalamos uma armadilha fotográfica (Trophy Cam HD 119537c, Bushnell) em cada ponto de amostragem, totalizando oito armadilhas por paisagem. Em frente a cada câmera foram colocadas pequenas quantidades de iscas (sal, banana, sardinha e bacon) no chão e em tubos de PVC furados e pendurados entre árvores (Figura 2), de maneira que as iscas dos tubos não fossem consumidas aumentando o tempo de atração. As iscas foram trocadas semanalmente. Um estudo piloto realizado em duas das paisagens de estudo demonstrou que o uso das iscas aumenta a detectabilidade sem alterar a ocupação ou abundância dos cachorros (dados não publicados), como observado em outros estudos (Gerber et al., 2012).

A amostragem foi realizada entre fevereiro e julho de 2015 , quando a câmera de cada ponto de amostragem ficou ativa por um período de 42 a 45 dias consecutivos. Os pontos de quatro paisagens foram amostrados simultaneamente, e os três grupos de quatro paisagens, consecutivamente. Devido a problemas com o funcionamento de algumas câmeras, o esforço amostral variou de 293 a 351 câmeras-dia por paisagem, e totalizou 4006 câmeras-dia entre todas as paisagens.

Os cachorros fotografados foram individualizados a partir da comparação das fotografias obtidas nas câmeras, usando características como cor, tamanho, tipo de pelagem e padrão de manchas (Figura 2) e posteriormente comparados com os cachorros fotografados nos domicílios (ver Material e Métodos - Pressão de Propágulos). O número de cachorros registrados em cada ponto de amostragem variou de 0 a 12 e em cada paisagem de 5 a 27 (Figura 3A,3B). 


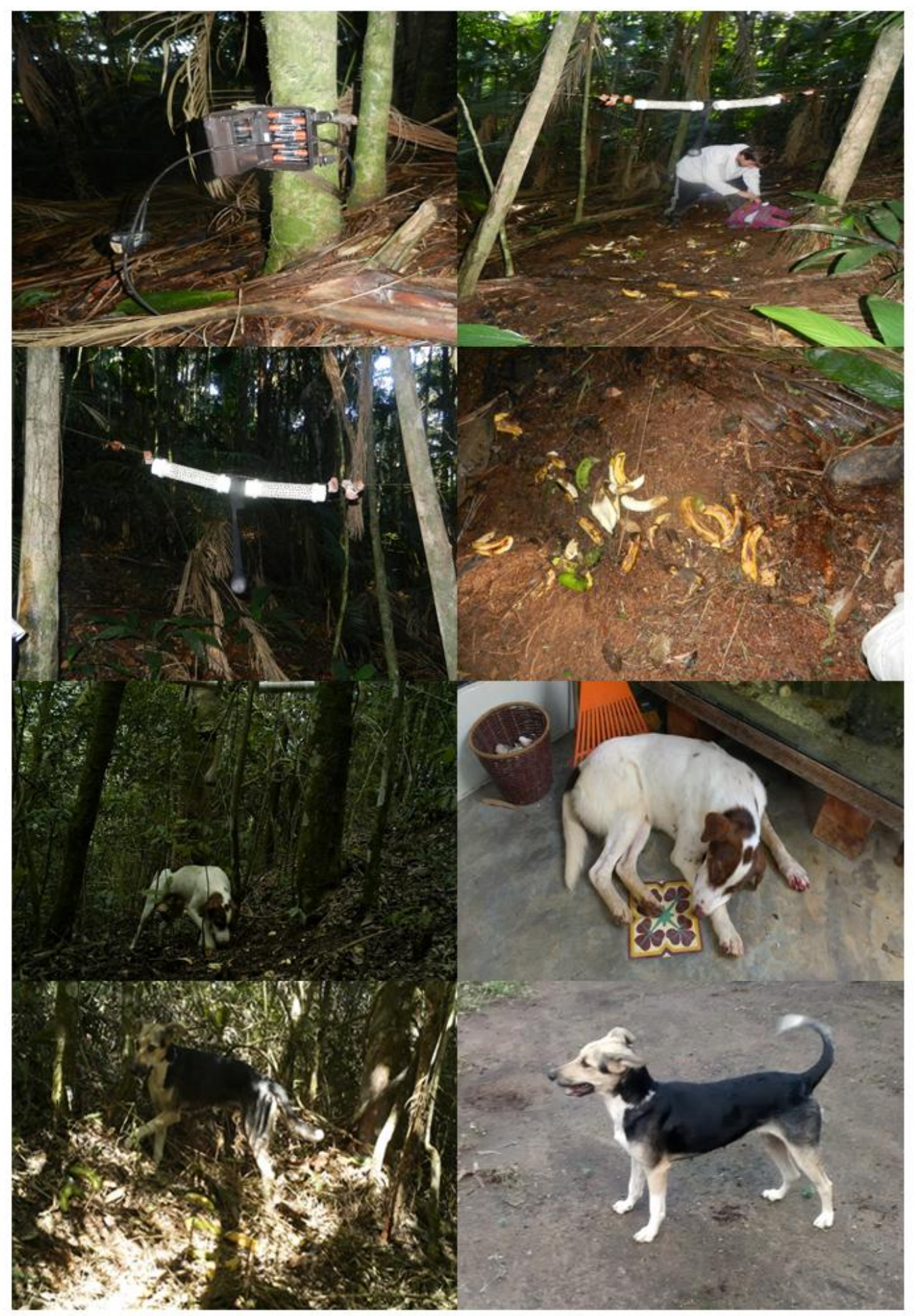

Figura 2: Disposição da armadilha fotográfica e das iscas nos pontos de amostragem, e dois exemplos de cachorros fotografados nos remanescentes florestais e posteriormente reconhecidos através das fotografias obtidas durante o censo da população de cachorros em todos os domicílios das paisagens de estudo. 

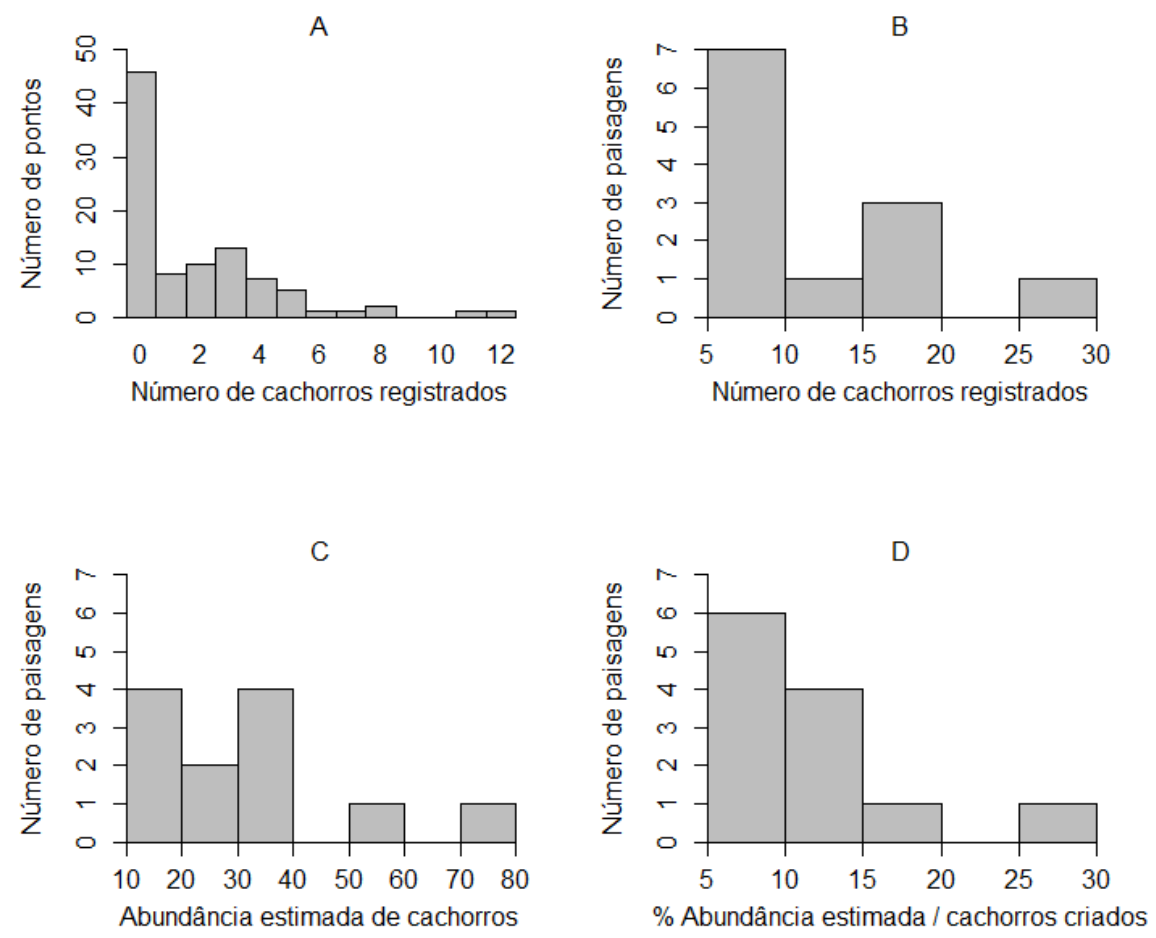

Figura 3: Histogramas do (A) número de cachorros registrados em cada ponto de amostragem, (B) número de cachorros registrados em cada paisagem, (C) abundância de cachorros estimada pelo modelo selecionado (Tabela 2) em cada paisagem, e (D) porcentagem da abundância estimada pelo modelo melhor ranqueado em relação ao número de cachorros criados em cada paisagem.

\subsubsection{Pressão de propágulos}

Para quantificar o número de cachorros criados pela população humana, os domicílios de cada paisagem foram mapeados com o uso de imagens do Google Earth. Durante a coleta de dados com as armadilhas fotográficas, cada um dos domicílios foi visitado em campo para a obtenção das coordenadas geográficas, contagem do número de cachorros criados (4082 no total) e registro fotográfico os cachorros para posterior comparação com as fotografias obtidas pelas armadilhas. Para 1512 cachorros (37\% do total), obtivemos informações detalhadas a partir da aplicação de questionários através de entrevistas com seus donos para caracterizar a população local de cachorros na região (ver Área de estudo; autorização do Comitê de Ética em Pesquisa - Seres Humanos do Instituto de Biociências da USP - parecer 981.535).

A partir desses dados, calculamos três variáveis para quantificar pressão de propágulos em cada paisagem: 
(a) densidade de cachorros criados (Den) - número de cachorros criados na paisagem, dividido pela área da paisagem ocupada por áreas abertas não florestais; isto é, pela área onde se concentram os domicílios dos moradores (Anexo 1). A densidade de cachorros criados variou de 0.04 a 0.83 cachorros/ha entre as 12 paisagens de estudo (Figura 4).

(b) distâncias entre os locais de criação dos cachorros e o fragmento de floresta nativo mais próximo - calculamos tanto a média (MediaDist) como a mediana (MedianaDist) destas distâncias entre todos os cachorros criados em uma paisagem. A média da distância dos locais de criação ao fragmento florestal mais próximo variou de 66 a 155 m, e a mediana desta distância de 52 a 145 $\mathrm{m}$, entre as 12 paisagens (Figura 4).

Os cálculos de distância dos locais de criação aos fragmentos e da quantidade de áreas abertas em cada paisagem foram feitos com o ArcGIS v10.1.

\subsubsection{Distúrbios relacionados à perda de habitat na escala de paisagens}

Para representar o grau de distúrbio associado à perda de habitat, calculamos três variáveis para cada paisagem:

(a) cobertura florestal nativa (CFN) - proporção da área da paisagem coberta por florestas nativas, que variou de 10 a $48 \%$ entre as 12 paisagens (Figura 4).

(b) cobertura florestal total (CFT) - proporção da área da paisagem coberta por florestas nativas e exóticas, que variou de 20 a 67\% entre as 12 paisagens (Figura 4).

(c) extensão de borda entre florestas nativas e áreas abertas (Borda) - que variou de 193 a 363 km entre as 12 paisagens (Figura 4).

Todas as variáveis foram calculadas com o software Fragstats v4.2.1.

\subsubsection{Esforço, época do ano e blocos de amostragem}

Além das variáveis espaciais relacionadas à pressão de propágulos e distúrbios, definimos também três variáveis temporais que poderiam ter relação com a probabilidade de detecção dos cachorros nos remanescentes florestais de cada paisagem:

(a) esforço amostral - soma em câmeras-dia do número de dias de amostragem em que cada uma das oito câmeras ficou ativa em cada uma das sessões de amostragem. 
(b) época do ano - época do ano (mais quente - meses fevereiro e março, ou mais fria - meses abril a julho) em que os remanescentes de cada paisagem foram amostrados, uma vez que estudos anteriores sugerem que os cachorros podem diminuir o número de incursões em períodos mais quentes (Ruiz-Izaguirre et al., 2014).

(c) blocos de amostragem - três blocos temporais consecutivos de amostragem, em cada um dos quais quatro paisagens foram amostradas simultaneamente.

A

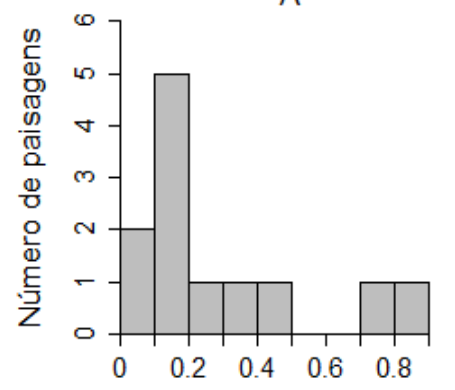

Densidade de cachorros criados

D

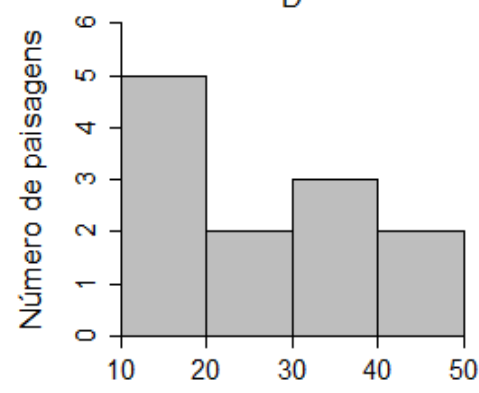

Proporção de floresta nativa
B

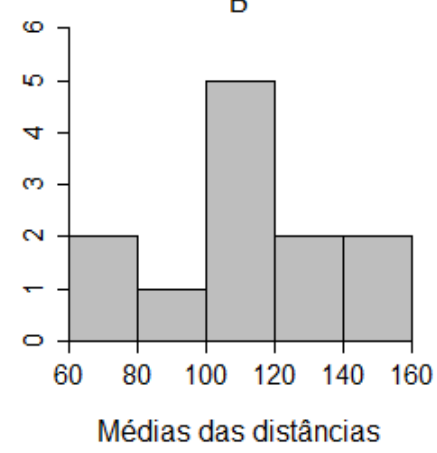

$\mathrm{E}$

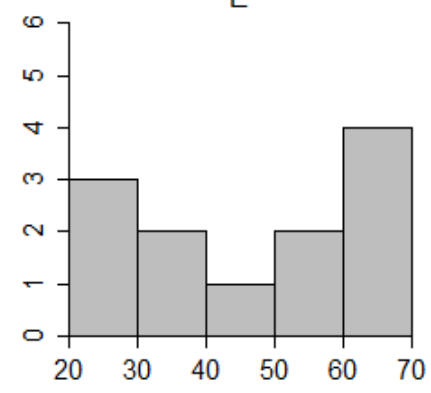

Proporção de floresta total

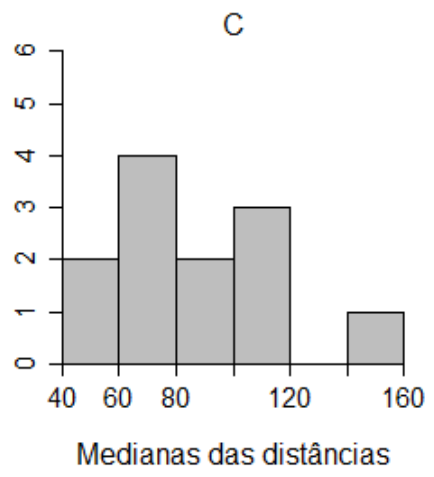

$\mathrm{F}$

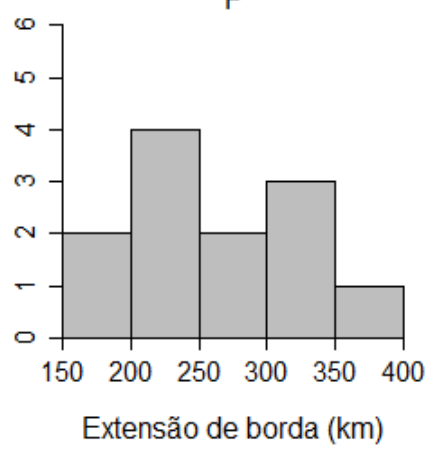

Figura 4: Histogramas das variáveis relacionadas à pressão de propágulos (A-C) e aos distúrbios associados à perda de habitat (D-F) entre as 12 paisagens de estudo. (A) Densidade de cachorros criados; (B) Média da distância dos locais de criação dos cachorros ao fragmento florestal mais próximo; (C) Mediana da distância dos locais de criação dos cachorros ao fragmento florestal mais próximo; (D) Proporção de floresta nativa; (E) Proporção de floresta total; (F) Extensão de borda entre floresta nativa e áreas abertas. 


\subsection{Análise de dados}

\subsubsection{Modelos de abundância}

Para investigar o efeito da pressão de propágulos e dos distúrbios associados à perda de habitat sobre o número de cachorros que utilizam remanescentes florestais em cada paisagem, foram utilizados modelos de abundância de uma temporada ( $N$-mixture models) (Royle, 2004), que derivam de modelos de ocupação (Mackenzie et al., 2002). Esses modelos estimam dois parâmetros, abundância $(\lambda)$ e probabilidade de detecção (p), a partir da contagem de indivíduos em cada sessão de amostragem em cada unidade amostral. Definimos como sessão de amostragem um período de seis dias, totalizando sete sessões de seis dias cada, sendo que em todas as sessões de amostragem as fotografias permitiram diferenciar quantos indivíduos foram registrados. Definimos como unidade amostral, cada uma das 12 paisagens, utilizando, portanto, conjuntamente os dados obtidos nos oito pontos de amostragem de cada uma delas.

A estratégia de análise baseou-se em duas etapas de seleção de modelos através do critério de informação de Akaike corrigido para pequenas amostras - AICc (Burnham e Anderson, 2002). Na primeira etapa, covariáveis relacionadas com o esforço de amostragem (câmeras-dia), a época do ano (época quente e época fria) e blocos de amostragem (três blocos de quatro paisagens amostradas concomitantemente) foram inseridas apenas no parâmetro probabilidade de detecção, mantendo-se a abundância constante. O conjunto de modelos candidatos incluiu seis modelos em que o parâmetro detectabilidade foi constante, em função de cada uma das três variáveis individualmente e em função aditiva de duas variáveis, sendo sempre o esforço e mais uma representando a época do ano ou os blocos de amostragem:

$p(.) \lambda($.

p(esforço) $\lambda($.

p(época) $\lambda($.

$\mathrm{p}($ blocos $) \lambda($.

p(esforço:época) $\lambda($.

p(esforço:blocos) $\lambda($.

Com a melhor maneira de modelar a detecção fixada, em uma segunda etapa covariáveis de pressão de propágulos e distúrbios associadas à perda de hábitat foram inseridas no parâmetro abundância. O conjunto de modelos candidatos incluiu 25 modelos em que o parâmetro abundância foi constante, em função de cada uma das seis variáveis (três de pressão de propágulo 
e três de distúrbios associadas à perda de hábitat) individualmente, em função aditiva de duas variáveis, sempre uma de pressão de propágulo e uma de distúrbios associadas à perda de hábitat (considerando todas as combinações possíveis entre variáveis dos dois grupos), e em função de interação considerando duas variáveis, sempre uma de pressão de propágulo e uma de distúrbios associadas à perda de hábitat (considerando todas as combinações possíveis entre variáveis dos dois grupos).

p(esforço:época) $\lambda($ (.)

p(esforço:época) $\lambda$ (pressão de propágulo)

p(esforço:época) $\lambda$ (distúrbios associadas à perda de hábitat)

p(esforço:época) $\lambda$ (pressão de propágulo:distúrbios associadas à perda de hábitat)

p(esforço:época) $\lambda$ (pressão de propágulo*distúrbios associadas à perda de hábitat)

Testamos a qualidade do ajuste do modelo melhor ranqueado através de um bootstrap paramétrico com 10000 reamostragens e a estatística qui-quadrado. O grau de correlação entre as variáveis de pressão de propágulos e as variáveis de distúrbios associadas à perda de hábitat, ou seja, entre variáveis que estiveram juntas em modelos candidatos, foi na maioria dos casos baixa $(r<0.4$; máximo $r=0.71$ ) e o grau de colinearidade foi sempre baixo (VIF $<2$ ) (Anexo 2).

\subsubsection{Tipos de distribuição de abundância e sessões de amostragem}

Os modelos utilizados podem assumir três tipos de distribuição de abundância: Poisson, binomial negativa e Poisson inflacionada de zeros (zero inflated Poisson). Para decidir qual a melhor distribuição, as análises descritas acima foram repetidas utilizando-se os três tipos (Anexo 3). A estabilidade dos melhores modelos de cada distribuição foi testada e estes modelos foram comparados por AICc. A distribuição Poisson foi mostrou-se mais adequada (Tabela S1, S2) e foi a distribuição utilizada nas análises apresentadas aqui. Similarmente, para testar se a duração e número/ duração das sessões influenciam os resultados, as análises descritas acima foram repetidas considerando sessões de 3, 4, 5, 7 e 8 dias (Anexo 4), sendo que os resultados são qualitativamente os mesmos de quando se usa sessões de 6 dias apresentadas aqui (Tabela S2; Figura S3).

Todas as análises foram feitas com o programa R (R.2.15.1, The R Foundation for Statistical Computing 2012). 


\section{RESULTADOS}

Foram registrados pelo menos 144 cachorros nas matas das 12 paisagens, com registros de cachorros em todas elas e em 51 dos 96 pontos de amostragem (53\%). Em 14 ocasiões (i.e. conjunto de fotos sequenciais de um mesmo indivíduo), não foi possível identificar se o indivíduo era um já registrado ou um indivíduo novo, porém foi possível constatar que eram indivíduos diferentes dos outros da mesma sessão de amostragem, não afetando as estimativas de abundância. Com as comparações entre as fotografias das armadilhas fotográficas e as fotografias dos cachorros criados nos domicílios foi possível identificar a procedência de 59 cachorros destes 144 cachorros (41\%). Esses indivíduos realizaram 272 incursões registradas pelas armadilhas fotográficas em remanescentes florestais (fotografias de indivíduos diferentes, ou do mesmo indivíduo em dias e/ou câmeras diferentes), com distâncias em linha reta do domicílio de criação ao ponto de amostragem variando de 94 a 3975 m (387.33 \pm 383.16$)$ (Figura 5).

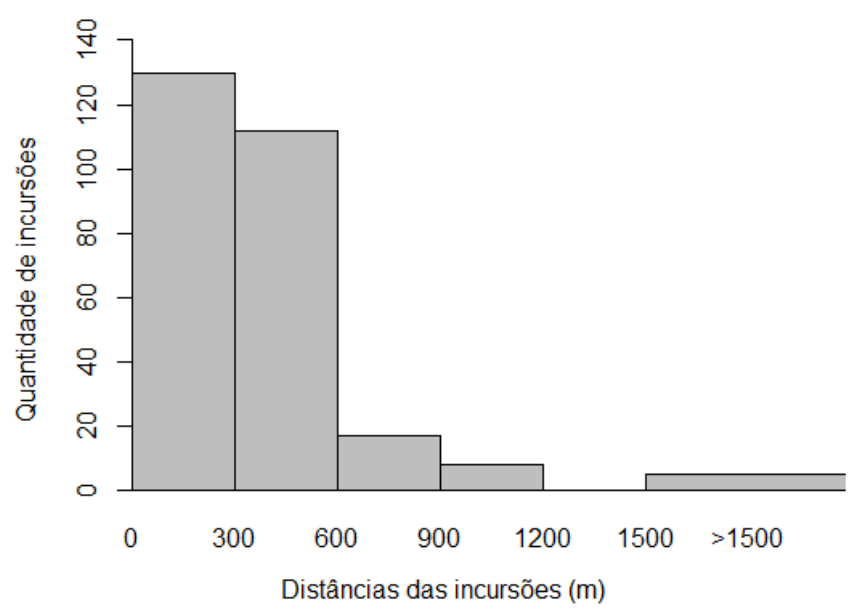

Figura 5: Histograma das distâncias das incursões (distância em linha reta do local de criação ao ponto de amostragem em remanescentes florestais) de 59 cachorros cujo local de criação foi identificado.

O único modelo selecionado para explicar a variação na detectabilidade de cachorros nos remanescentes florestais das 12 paisagens de estudo (Tabela 1), indica que a detectabilidade é maior quanto maior o esforço de amostragem e durante a época mais fria (Figura 6). As estimativas para a detectabilidade segundo este modelo variaram de 0.11 a $0.38(0.29 \pm 0.10)$. 

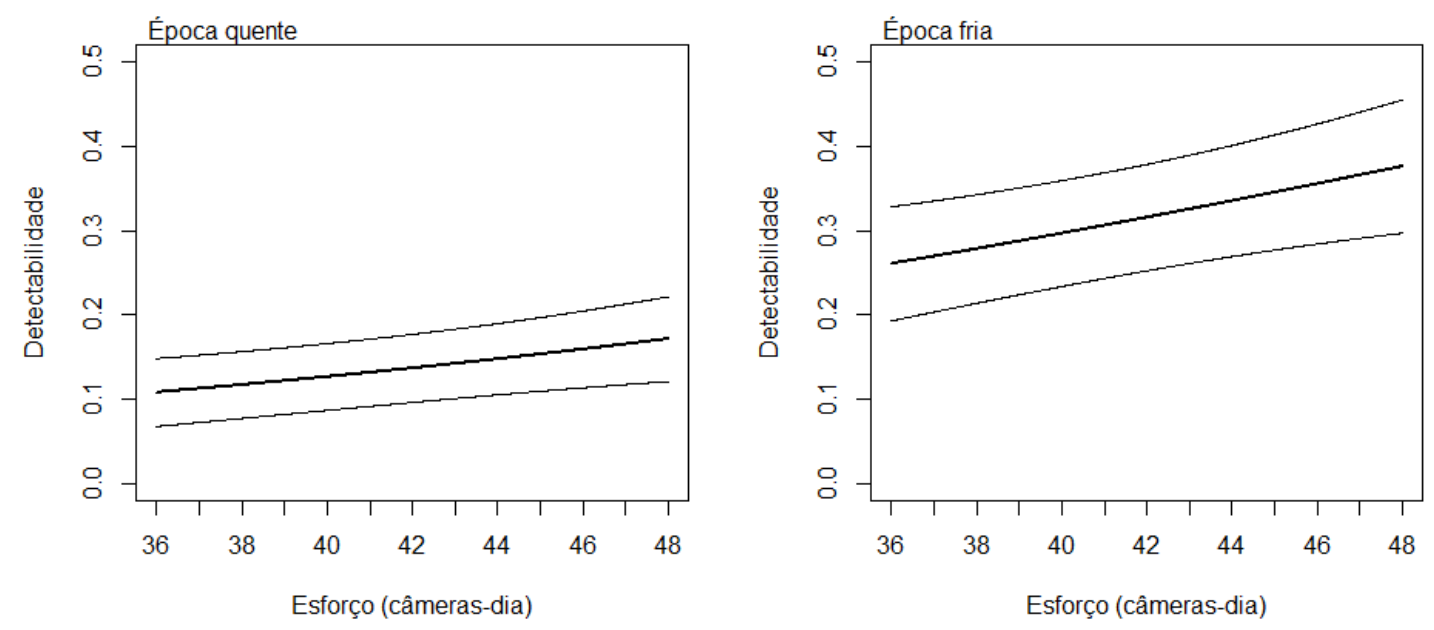

Figura 6: Variação da detectabilidade de cachorros nos remanescentes florestais em função do esforço amostral para a época quente e a época fria estimada pelo modelo selecionado (Tabela 1). As linhas escuras representam as estimativas do modelo e as linhas claras os erros padrão.

Tabela 1: Resultados da seleção de modelos da detectabilidade de cachorros em remanescentes florestais em função do esforço amostral (esforço), épocas de amostragem (época) e blocos de amostragem (bloco). Em todos os modelos o parâmetro abundância foi mantido constante $\lambda($.). Os modelos estão ordenados do menor para o maior AICc. São apresentadas informações do número de parâmetros (K), critério de informação de Akaike corrigido para pequenas amostras (AICc), diferença de $\mathrm{AICc}$ entre os modelos e o modelo melhor ranqueado ( $\triangle \mathrm{AICc}$ ), peso de evidência ( $\omega \mathrm{i})$, log likelihood (LL) e valores dos coeficientes das covariáveis com seus respectivos erros-padrão.

\begin{tabular}{|c|c|c|c|c|c|c|c|c|c|}
\hline \multirow[b]{2}{*}{ Modelo } & \multirow[b]{2}{*}{ K } & \multirow[b]{2}{*}{ AICc } & \multirow[b]{2}{*}{$\Delta \mathrm{AICC}$} & \multirow[b]{2}{*}{$\omega \mathbf{i}$} & \multirow[b]{2}{*}{ LL } & \multicolumn{4}{|c|}{ Coeficientes } \\
\hline & & & & & & Esforço & Época fria & Bloco 2 & Bloco 3 \\
\hline p(esforço:época) & 4 & 366.23 & 0.00 & 0.92 & -176.26 & $0.04(0.03)$ & $1.07(0.28)$ & - & - \\
\hline p(esforço:blocos) & 5 & 372.16 & 5.93 & 0.05 & -176.08 & $0.05(0.03)$ & - & $1.18(0.34)$ & $0.98(0.32)$ \\
\hline p(esforço) & 3 & 373.18 & 6.95 & 0.03 & -182.09 & $0.04(0.03)$ & - & - & - \\
\hline p(época) & 3 & 441.30 & 75.07 & $<0.01$ & -216.15 & - & $0.86(0.23)$ & - & - \\
\hline p(bloco) & 4 & 445.99 & 79.77 & $<0.01$ & -216.14 & - & - & $0.87(0.26)$ & $0.84(0.25)$ \\
\hline $\mathrm{p}()$. & 2 & 449.43 & 83.2 & $<0.01$ & -222.05 & - & - & - & - \\
\hline
\end{tabular}

Já o único modelo selecionado para explicar a variação na abundância de cachorros nos remanescentes florestais entre as 12 paisagens de estudo (Tabela 2 ) indica que a abundância dos cachorros é maior quanto menor a cobertura florestal total e maior a densidade de cachorros criados na paisagem (Figura 7). Além desse modelo, outros quatro foram considerados mais plausíveis que o nulo, todos contendo uma das duas variáveis de cobertura florestal ou a variável 
de densidade de cachorro criados (ou ambas). Nesses modelos, os efeitos das variáveis são os mesmos que no modelo melhor ranqueado.

A soma dos pesos de evidência dos modelos com variáveis de pressão de propágulos e dos modelos com variáveis de distúrbios associados à perda de habitat é bastante similar (Tabela 3), novamente indicando que os dois tipos de determinantes são igualmente importantes para definir a intensidade de invasão de cachorros em remanescentes florestais. Entre as variáveis de pressão de propágulos, modelos contendo a variável densidade de cachorros criados tiveram pesos de evidência muito maiores, correspondendo a praticamente $100 \%$ do peso total. Entre as variáveis de distúrbios associados à perda de habitat, no entanto, a importância da variável cobertura florestal total foi bem maior, seguida da variável cobertura florestal nativa e da variável extensão de bordas (esta última com um peso de evidência bastante baixo).

As estimativas de abundância de cachorros em remanescentes florestais, segundo o modelo selecionado, variaram de 12 a 79 entre as paisagens (30.9 \pm 19.5) (Figura 3C). Assim, a proporção da abundância estimada de cachorros que invadem remanescentes florestais em relação ao total de cachorros criados em cada paisagem variou de 6 a $20.9 \%$ (11.8 \pm 6.33 ) (Figura 3D).
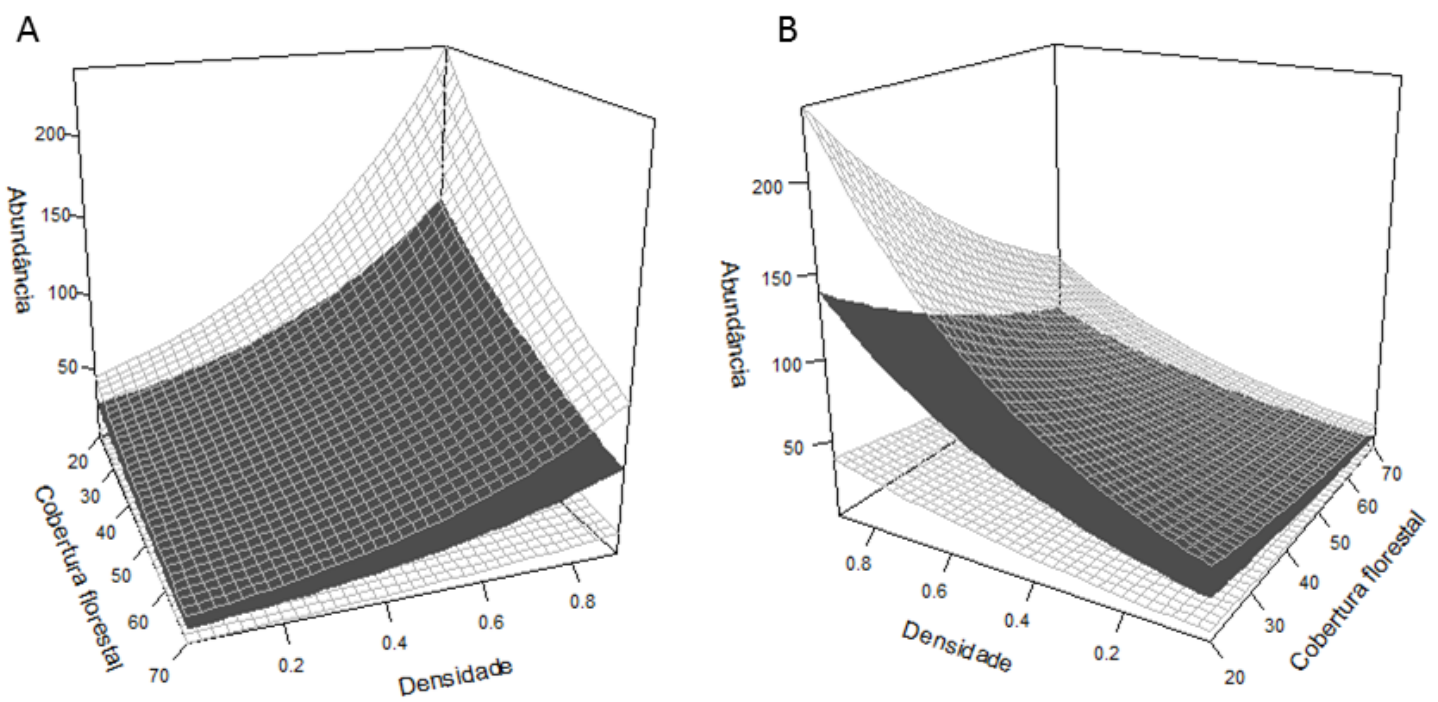

Figura 7: Variação da abundância de cachorros nos remanescentes florestais em função da cobertura florestal total e da densidade de cachorros criados na paisagem, segundo o modelo selecionado (Tabela 1). Duas perspectivas do mesmo gráfico são mostradas para melhor visualização. Os planos sólidos representam os valores estimados pelo modelo e os planos transparentes os erros padrão. 
Tabela 2: Resultado da seleção de modelos da abundância de cachorros nos remanescentes florestais em função de variáveis de pressão de propágulos e de distúrbios associados à perda de hábitat. Em todos os modelos o parâmetro detectabilidade teve como covariáveis esforço amostral e época de amostragem p(esforço:época). Os modelos estão ordenados do menor para o maior AICc. São apresentadas informações do número de parâmetros (K), critério de informação de Akaike corrigido para pequenas amostras (AICC), diferença de AICc entre os modelos e o modelo melhor ranqueado $(\triangle A I C C)$, peso de evidência (wi), log likelihood (LL) e valores dos coeficientes das variáveis com seus respectivos erros-padrão. Den: densidade de cachorros criados, MediaDist: média das distâncias entre os locais de criação dos cachorros e o fragmento de floresta nativo mais próximo, MedianaDist: mediana das distâncias entre os locais de criação dos cachorros e o fragmento de floresta nativo mais próximo, CFT: cobertura florestal total, CFN: cobertura florestal nativa, Borda: extensão de borda entre florestas nativas e áreas abertas.

\begin{tabular}{|c|c|c|c|c|c|c|c|c|}
\hline \multirow[b]{2}{*}{ Modelos } & \multirow[b]{2}{*}{ K } & \multirow[b]{2}{*}{ AICc } & \multirow[b]{2}{*}{$\Delta \mathrm{AICc}$} & \multirow[b]{2}{*}{$\omega \mathbf{i}$} & \multirow[b]{2}{*}{ LL } & \multicolumn{3}{|c|}{ Coeficientes } \\
\hline & & & & & & Var1 (SE) & Var2 (SE) & Interação (SE) \\
\hline$\lambda($ CFT+Den) & 6 & 349.31 & 0.00 & 0.82 & -160.26 & $-0.0192(0.0048)$ & $1.8890(0.3483)$ & - \\
\hline$\lambda($ CFN+Den) & 6 & 353.71 & 4.39 & 0.09 & -162.45 & $-0.0230(0.0073)$ & $1.7437(0.3566)$ & - \\
\hline$\lambda($ Den) & 5 & 353.77 & 4.45 & 0.09 & -166.88 & $1.6553(0.3520)$ & - & - \\
\hline$\lambda(\text { CFT*Den })^{*}$ & 7 & 362.48 & 13.16 & 0.00 & -160.24 & $-0.0205(0.0080)$ & 1.6900 (1.0779) & $0.0036(0.0184)$ \\
\hline$\lambda(\mathrm{CFT})$ & 5 & 363.24 & 13.92 & 0.00 & -171.62 & $-0.0177(0.0056)$ & - & - \\
\hline$\lambda(\mathrm{CFN})$ & 5 & 364.26 & 14.94 & 0.00 & -172.13 & $-0.0231(0.0079)$ & - & - \\
\hline$\lambda$ (MedianaDist) & 5 & 365.56 & 16.25 & 0.00 & -172.78 & $0.0094(0.0035)$ & - & - \\
\hline$\lambda()$. & 4 & 366.23 & 16.91 & 0.00 & -176.26 & - & - & - \\
\hline$\lambda\left(\right.$ CFN $^{*}$ Den $)$ & 7 & 366.76 & 17.45 & 0.00 & -162.38 & $-0.0188(0.0119)$ & $2.1433(0.9685)$ & $-0.0120(0.0270)$ \\
\hline$\lambda($ CFN+MedianaDist $)$ & 6 & 369.41 & 20.10 & 0.00 & -170.31 & $-0.0180(0.0080)$ & $0.0069(0.0037)$ & - \\
\hline$\lambda$ (MediaDist) & 5 & 369.88 & 20.57 & 0.00 & -174.94 & 0.0059 (0.0039) & - & - \\
\hline$\lambda($ CFT+MedianaDist) & 6 & 370.92 & 21.61 & 0.00 & -171.06 & $-0.0137(0.0070)$ & $0.0043(0.0044)$ & - \\
\hline$\lambda($ CFT+MediaDist) & 6 & 372.00 & 22.69 & 0.00 & -171.60 & $-0.0202(0.0075)$ & $-0.0025(0.0050)$ & - \\
\hline$\lambda($ CFN+MediaDist $)$ & 6 & 372.47 & 23.16 & 0.00 & -171.84 & $-0.0210(0.0084)$ & $0.0028(0.0041)$ & - \\
\hline$\lambda($ CFN*MedianaDist) & 7 & 435.33 & 86.02 & 0.00 & -196.67 & $0.0560(0.0138)$ & $0.0347(0.0039)$ & $-0.0009(3 e-5)$ \\
\hline$\lambda$ (Borda) & 5 & 566.68 & 217.37 & 0.00 & -273.34 & $-3 e-16(1 e-5)$ & - & - \\
\hline$\lambda($ Borda+MediaDist) & 6 & 575.48 & 226.17 & 0.00 & -273.34 & $-3 e-16(1 e-5)$ & $7 e-18(0.0147)$ & - \\
\hline$\lambda($ Borda+MedianaDist) & 6 & 575.48 & 226.17 & 0.00 & -273.34 & $-3 e-16(1 e-5)$ & $6 e-18(0.0143)$ & - \\
\hline$\lambda($ Borda+Den) & 6 & 575.48 & 226.17 & 0.00 & -273.34 & $-3 e-16(1 e-5)$ & $3 e-20(1.7900)$ & - \\
\hline$\lambda($ CFN*MediaDist) & 7 & 588.68 & 239.37 & 0.00 & -273.34 & $1 \mathrm{e}-18(0.0211)$ & $7 e-18(0.0122)$ & $-3 e-16(\mathrm{NaN})$ \\
\hline$\lambda\left(\right.$ CFT $^{*}$ MedianaDist $)$ & 7 & 588.68 & 239.37 & 0.00 & -273.34 & $2 e-18(0.0248)$ & $6 e-18(0.0155)$ & $-2 \mathrm{e}-16(\mathrm{NaN})$ \\
\hline$\lambda\left(\right.$ CFT $^{*}$ MediaDist $)$ & 7 & 588.68 & 239.37 & 0.00 & -273.34 & $5 e-19(0.0261)$ & $1 \mathrm{e}-18(0.0158)$ & $2 \mathrm{e}-16(\mathrm{NaN})$ \\
\hline$\lambda($ Borda*Den) & 7 & 588.68 & 239.37 & 0.00 & -273.34 & $-6 e-17(1 e-5)$ & $5 e-21(1.7915)$ & $4 e-16(1 e-5)$ \\
\hline$\lambda$ (Borda*MediaDist) & 7 & 588.68 & 239.37 & 0.00 & -273.34 & $-3 e-16(1 e-5)$ & $7 e-18(0.0147)$ & $0.0(1 e-5)$ \\
\hline$\lambda($ Borda*MedianaDist) & 7 & 588.68 & 239.37 & 0.00 & -273.34 & $-3 e-16(1 e-5)$ & $6 e-18(0.0143)$ & $0.0(1 e-5)$ \\
\hline
\end{tabular}


Tabela 3: Somas dos pesos de evidência dos modelos de abundância de cachorros em remanescentes florestais em que estão presentes cada uma das variáveis de pressão de propágulos e de distúrbios associados à perda de habitat. Den: densidade de cachorros criados, MediaDist: média das distâncias entre os locais de criação dos cachorros e o fragmento de floresta nativo mais próximo, MedianaDist: mediana das distâncias entre os locais de criação dos cachorros e o fragmento de floresta nativo mais próximo, CFT: cobertura florestal total, CFN: cobertura florestal nativa, Borda: extensão de borda entre florestas nativas e áreas abertas.

\begin{tabular}{llc}
\hline & & Soma wi \\
\hline \multirow{3}{*}{ Pressão de propágulos } & Den & 0.998 \\
& MediaDist & $<0.001$ \\
& MedianaDist & $<0.001$ \\
& Total & 0.998 \\
Distúrbios associados à & CFT & 0.820 \\
perda de habitat & CFN & 0.091 \\
& Borda & $<0.001$ \\
& Total & 0.911 \\
\hline
\end{tabular}




\section{DISCUSSÃO}

Pressão de propágulos (Lockwood et al., 2005; Colautti et al., 2006; Simberloff, 2009; Blackburn et al., 2013) e distúrbios (Byers, 2002; Crooks et al., 2011; Jauni et al., 2015; Gantchoff \& Belant, 2015) estão entre os determinantes do sucesso de invasões biológicas mais importantes para uma grande variedade de grupos animais e vegetais em diferentes ambientes, mas poucos trabalhos empíricos os consideraram simultaneamente, e a maioria destes apresenta algum tipo de limitação. Através de amostragem na escala da paisagem, da consideração de distúrbios em escala ampla e da pressão de propágulo quantificada diretamente, evitando correlações entre os diferentes fatores, esse trabalho investigou a importância relativa da pressão de propágulos e de distúrbios associados à perda de habitat como determinantes da invasão por cachorros, uma das espécies invasoras mais bem distribuídas no mundo (Gompper, 2014) e de grande impacto sobre a fauna silvestre (Bellard et al., 2016b). Nossos resultados indicam que, como proposto teoricamente e corroborado em trabalhos empíricos (Simberloff, 2009; Jauni et al., 2015), quanto maior a pressão de propágulos, ou quanto maior o nível de distúrbio, mais intensa é a invasão de florestas nativas por cachorros. Mais importante, no entanto, nossos resultados indicam que ambos os determinantes são igualmente importantes para a intensidade da invasão, e sugere que os efeitos dos dois fatores são aditivos, não havendo evidências de sinergia entre eles. Além disso, pudemos constatar que, entre as variáveis utilizadas para quantificar a pressão de propágulos, a densidade de indivíduos (relacionada ao tamanho do propágulo) foi mais importante que sua distribuição espacial, e entre as variáveis relacionadas à perda de habitat, a cobertura florestal (total ou nativa) foi mais importante que a extensão de bordas, na definição da intensidade da invasão. Por fim, também observamos que os cachorros são mais fáceis de serem detectados nos remanescentes florestais em épocas de temperatura mais amena. Nos próximos parágrafos, iremos discutir as implicações desses resultados para a teoria de invasões biológicas e, especificamente, para a invasão por cachorros, sugerindo possíveis mecanismos associados aos padrões encontrados. Por fim, iremos discutir as implicações dos resultados para o manejo e conservação da biodiversidade em paisagens modificadas pelo homem.

Os efeitos positivos observados da pressão de propágulos e de distúrbios sobre a intensidade de invasão por cachorros estão de acordo com a vasta literatura sobre determinantes de invasões biológicas (revisões em Simberloff, 2009; Jauni et al., 2015). No entanto, nosso trabalho contribui de maneira inovadora para a compreensão dos determinantes de invasões, por uma série de razões. Não só porque a grande maioria dos trabalhos anteriores não consideraram os dois 
determinantes conjuntamente (Lowry et al., 2013), mas também porque poucos trabalhos analisaram distúrbios em escalas mais amplas e/ou quantificaram diretamente a pressão de propágulos (Simberloff, 2009), e a maioria deles focou em plantas (Lowry et al., 2013). Apenas mais recentemente, alguns trabalhos têm quantificado distúrbios em escalas mais amplas como nós fizemos, utilizado variáveis associadas à estrutura da paisagem, mas todos eles foram realizados com espécies de plantas (Vilà \& Ibañez, 2011; Gonzáles-Moreno et al., 2014; Thomas \& Moloney, 2015). Além disso, quando a pressão de propágulos foi considerada conjuntamente como um determinante da invasão, foi estimada indiretamente a partir da própria estrutura da paisagem (e.g. cobertura de área agrícola, distância a áreas perturbadas) (Gonzáles-Moreno et al., 2013; Thomas \& Moloney, 2015), levando a correlações entre as estimativas de pressão de propágulos e distúrbios e dificultando a avaliação da importância relativa dos diferentes determinantes. Como estimamos pressão de propágulos diretamente a partir da contagem e localização dos cachorros criados nas paisagens, e essas estimativas não foram fortemente correlacionadas às estimativas do grau de distúrbio associado à perda de habitat, nossos resultados permitem inferir com maior segurança que a perda de habitat pode ser tão importante quanto a pressão de propágulos para determinar a intensidade das invasões.

Nossos resultados também sugerem que os efeitos destes dois principais determinantes são aditivos, não atuando sinergicamente na determinação da intensidade das invasões. Alguns entre os poucos trabalhos que avaliaram a potencial sinergia entre estes fatores encontraram evidências para uma interação positiva entre pressão de propágulos e distúrbios, mas em todos os casos foram considerados distúrbios em escala local e espécies invasoras de plantas (Britton-Simmons \& Abbott, 2008; Eschtruth \& Battles, 2009; Warren et al., 2012) ou invertebrados marinhos sésseis (Clark \& Johnston, 2009). Nesses casos, as interações provavelmente ocorrem porque existe um efeito dos distúrbios locais sobre o estabelecimento e/ou sobrevivência dos propágulos, ou seja, quanto maior o distúrbio local, maior a chance que um propágulo que atinja o local de fato se estabeleça e sobreviva. No caso dos cachorros, que são fortemente subsidiados pela população humana, os distúrbios associados à perda de habitat em escala ampla podem facilitar o acesso aos remanescentes florestais, mas sem interferir na sobrevivência dos cachorros. Estudos futuros com outras espécies animais que não sejam subsidiadas pelo homem são necessários para avaliar se, em todos os casos, distúrbios associados à perda de habitat na escala da paisagem não interagem sinergicamente com a pressão de propágulos para o sucesso de invasões biológicas. É possível que para espécies não subsidiadas, mesmo distúrbios em escala ampla possam afetar, não só o acesso, 
mas o estabelecimento ou sobrevivência de propágulos, por afetar a qualidade dos habitats remanescentes, por exemplo, através dos efeitos de borda.

Como estimamos a pressão de propágulos e os distúrbios a partir de mais de uma métrica, nossos resultados permitem que levantemos algumas hipóteses mais prováveis sobre os processos por trás dos efeitos destes determinantes. Em relação à pressão de propágulos, nossos resultados indicam que a densidade de cachorros é mais importante que a distribuição espacial dos indivíduos em relação à proximidade aos remanescentes florestais. Isso indica que quanto maior a população da espécie invasora, maior a chance de encontrarmos indivíduos com características que os tornem potenciais invasores (Blackburn et al., 2015). Essa hipótese está de acordo com os poucos estudos sobre as características individuais dos cachorros que os fazem ter maior área de vida e, portanto, maior probabilidade de invadirem áreas de vegetação nativa. Estes estudos sugerem que machos não castrados (Sparkes et al., 2014), jovens adultos (van Bommel \& Johnson, 2014), certas raças e boas condições de saúde (Meek, 1999) têm áreas de vida maiores, indicando que, de fato, quanto maior a população, maior a chance de encontrar indivíduos com essas características. Está também de acordo com estimativas de áreas de vida (entre 31 e 1160 ha, van Bommel \& Johnson, 2014) e distâncias de incursões obtidas em nosso trabalho e em outros estudos com rádio colares (1.9km, Sepúlveda et al., 2015; 995 m, Ruiz-Izaguirre et al., 2015), que indicam que os cachorros realizam deslocamentos relativamente grandes. Assim, não necessariamente cachorros invadem apenas remanescentes próximos ao local de criação, fazendo com que a distribuição espacial dos locais de criação seja menos importante como determinante das invasões.

Com relação às métricas de distúrbios associados à perda de habitat, a cobertura florestal (total e nativa) foi mais importante do que a extensão de bordas, e a cobertura florestal total mais importante do que a cobertura florestal nativa, na determinação da intensidade de invasão. Quanto mais florestas na paisagem, independente da extensão de bordas, menor é a intensidade da invasão, permitindo levantar a hipótese de que as áreas abertas na paisagem facilitam os deslocamentos dos cachorros e assim o acesso aos remanescentes florestais. De fato, um estudo com rádio colares GPS (Sepúlveda et al., 2015) demonstrou que cachorros selecionam preferencialmente áreas abertas (pastagens) em relação a áreas de florestas temperadas para se deslocar e sugere que as florestas são barreiras aos movimentos dos cachorros. $\mathrm{O}$ fato de cachorros serem considerados um efeito de borda, sendo mais comuns nas bordas do que nos interiores de áreas de vegetação nativa (Srbek-Araujo \& Chiarello, 2008; Lacerda et al., 2009), 
também corrobora a hipótese de que as florestas dificultam o seu deslocamento. Desta maneira, dado que os cachorros são capazes de realizar grandes deslocamentos em áreas abertas, a existência de barreiras florestais ao movimento dos cachorros (cobertura florestal) parece ser mais importante do que a quantidade de pontos de acesso às florestas nativas (extensão de bordas) para a intensidade de invasão.

Se esta hipótese estiver correta, seria possível limitar a invasão de cachorros alterando não necessariamente a quantidade de florestas, mas a distribuição espacial delas, maximizando a formação de barreiras aos movimentos. Estudos futuros que comparem a movimentação e intensidade da invasão por cachorros em paisagens com mesma cobertura florestal em diferentes configurações espaciais permitiriam testar a hipótese. Para espécies invasoras não subsidiadas pelo homem, em que a qualidade do habitat e a disponibilidade de recursos sejam aumentadas pela conversão de florestas em áreas abertas (i.e. independentemente da densidade da população humana nessas áreas), é possível, no entanto, que o mecanismo por trás do efeito negativo da cobertura florestal sobre a intensidade de invasão seja populacional em vez de individual (movimentação do indivíduo). Nestes casos, menor cobertura florestal pode significar populações da espécie invasora nas áreas abertas maiores e menos isoladas (Umetsu \& Pardini, 2007), facilitando o "spillover" de indivíduos para áreas de florestas (Tscharntke et al., 2012) e/ou uma dinâmica populacional fonte-dreno entre áreas abertas e florestas (Pulliam, 1988; Thomson, 2007), intensificando a invasão.

Secundariamente, nossos resultados também indicam que a detecção de cachorros em pontos de amostragem nas florestas é influenciada pela temperatura, sendo que os maiores valores de detecção ocorrem em épocas de temperaturas mais amenas. Portanto, a atividade e movimentação dos cachorros devem aumentar e, como consequência, a detecção em pontos amostrais incluídos nas áreas de vida dos cachorros, ou seja, em pontos ocupados, é também maior nessas épocas. Alguns trabalhos de fato sugerem que a atividade de cachorros é menor em temperaturas elevadas (Berman \& Dunbar, 1983; Ruiz-Izaguirre et al., 2015). Assim, trabalhos futuros sobre cachorros envolvendo a detecção dos indivíduos por armadilhas fotográficas, ou relacionados ao uso do habitat e padrões de movimentação e atividade, independente da metodologia utilizada (e.g. rádio colares), devem levar em consideração as variações de temperatura sazonais e diárias, considerando que os métodos podem ser mais eficientes em temperaturas mais amenas. 
Devido à amostragem em escala da paisagem, utilização de modelos de abundância por meio da individualização dos cachorros e um censo completo da população de cachorros, nós pudemos caracterizar pela primeira vez a invasão dessa espécie em termos populacionais e estimar uma proporção mínima de cachorros que invadem os remanescentes florestais em relação ao total de cachorros criados. Os números que obtivemos são impressionantes, com até 80 indivíduos invasores em uma única paisagem e até $21 \%$ de cachorros invasores em relação a todos os cachorros criados, certamente posicionando o cachorro como o carnívoro mais abundante nas matas da região. De fato, outros estudos também constataram que os cachorros são comuns em remanescentes florestais (Silva-Rodríguez \& Sieving, 2012; Cassano et al., 2014; Frigeri et al., 2014; Farris et al., 2015), sendo inclusive a espécie de carnívoro mais registrada em outra região da Mata Atlântica (Srbek-Araujo \& Chiarello, 2008).

Esses números são preocupantes, dado que o cachorro representa inúmeras ameaças para a fauna silvestre. Por todo o mundo, há registros de cachorros predando desde pequenos animais, como roedores e aves, até cervídeos de maior porte (revisão em Young et al., 2011). Potencialmente mais danosos que os efeitos letais da predação são os efeitos não letais (Preisser et al., 2005), que podem ser entendidos como paisagens de medo que levam a alterações fisiológicas e/ ou comportamentais (e.g. maior tempo gasto em vigilância) que diminuem a sobrevivência ou condição corporal dos indivíduos, dado o risco potencial de predação. Imagina-se que estes efeitos não letais sejam ainda mais intensos quando os predadores são subsidiados pelo homem, apresentando altas densidades populacionais (Gompper \& Vanak, 2008), e em predadores altamente vocais, como os cachorros. Entre os potenciais efeitos não letais causados por cachorros, já foram comprovadas a diminuição no sucesso reprodutivo (Gingold et al., 2009), tanto em quantidade quanto qualidade da ninhada (Sheriff et al., 2009), e a alteração nos padrões de atividade (Zapata-Ríos \& Branch, 2016) e uso de habitat (Silva-Rodríguez \& Sieving, 2012). Na região de estudo, muitos donos de cachorros relataram que seus cachorros perseguem e/ou já foram machucados por animais nativos, o que indica a ameaça por predação, mesmo que não letal. Outras interações negativas entre cachorros e a fauna silvestre já relatadas incluem a competição por exploração (Butler \& duToit, 2002) e interferência (Vanak \& Gomper, 2010) e a transmissão de doenças (Woodroffe, 1999; Cleaveland et al., 2000). Com relação à transmissão de doenças, o cachorro ameaça não apenas a fauna, mas também a população humana local através de zoonosoes (Fortes et al., 2011; Curi et al., 2014), já que conecta diferentes ambientes e espécies em ciclos de transmissão de doenças (Macpherson, 2005) por frequentar tantos ambientes alterados onde as populações humanas se concentram quando ambientes naturais 
onde se concentram as populações de animais silvestres. Nesse sentido, os relatos de donos de cachorros na região de estudo também são preocupantes, já que é comum a falta de vacinação e o não uso de remédios contra parasitas, como vermes e carrapatos.

\subsection{Implicações para a conservação}

Em conjunto, nossos resultados demonstram a necessidade urgente de ações que visem controlar a invasão de cachorros em remanescentes de vegetação nativa e fornece diretrizes para embasar o planejamento dessas ações. Na Mata Atlântica, assim como em outras florestas tropicais do mundo, mais de $90 \%$ da vegetação remanescente não é protegida por reservas (Ribeiro et al., 2009), estando concentrada em regiões rurais, como a de nosso estudo. Nessas áreas, o número de cachorros criados é grande (este estudo; Campos et al., 2007; Silva-Rodríguez \& Sieving, 2012), e nossos resultados indicam que uma grande proporção da população pode ser formada por indivíduos que costumeiramente invadem remanescentes florestais, mesmo que não residam próximos a eles. Além disso, a intensidade da invasão é maior em paisagens mais desmatadas (independentemente do número de cachorros criados), precisamente as que concentram as ameaças à conservação da biodiversidade.

Estes resultados sugerem que planos de ação de controle das invasões devem levar em conta questões relacionadas à estrutura da paisagem. Métodos tradicionais de controle populacional frequentemente recomendados (Silva-Rodriguez \& Sieving, 2012; Hughes \& Macdonald, 2013; Farris et al., 2015), como captura, castração de indivíduos e restrição de movimentos, devem ser

implementados, uma vez que de fato a pressão de propágulos, e em especial o número de indivíduos, é um determinante importante da intensidade de invasão. Porém, essas ações devem ser priorizadas nas paisagens mais desmatadas. Além disso, nossos dados sugerem que o valor de mecanismos que estimulem a manutenção e restauração de florestas é maior do que o reconhecido usualmente, pois além de favorecerem o tamanho e a conexão das populações das espécies nativas, também devem diminuir os impactos negativos das invasões biológicas. Particularmente interessante do ponto de vista de viabilidade, é a possibilidade de se manejar a estrutura de paisagens rurais para evitar o impacto das invasões por cachorros através de florestas plantadas, de modo a barrar estrategicamente a movimentação de cachorros em áreas de maior interesse, e ao mesmo tempo permitir ganhos econômicos a partir da exploração da madeira. 
Por outro lado, nosso trabalho sugere que os efeitos negativos atribuídos à perda de habitat ou sobre-exploração sobre a fauna silvestre, especialmente a fauna de mamíferos de maior porte, possam ser, pelo menos em parte, causados pelo aumento das invasões de cachorros e não diretamente pelo desmatamento ou pela caça. Além de ser um determinante importante do sucesso de invasões biológicas, como demonstramos aqui, a perda de habitat é também considerada a principal causa do declínio da biodiversidade no mundo (Foley et al., 2005). Similarmente, a sobre-exploração através da caça é uma ameaça das mais importante a espécies de mamíferos (González-Suárez \& Revilla, 2014), e está associada à densidade da população humana e, portanto, à densidade de cachorros criados. Como a maioria dos trabalhos que investigam a crise de biodiversidade restringe-se a apenas uma ameaça (Murphy \& Romanuk, 2014) e essas ameaças são correlacionadas e devem interagir sinergicamente (Brook et al., 2008), o empobrecimento da biota pode em muitos casos ser causados por ameaças outras além das estudadas. Estudos futuros devem levar em consideração múltiplas ameaças e suas possíveis interações, especialmente quando essas forem potencialmente correlacionadas, caso da perda de habitat, caça e invasões biológicas. Só assim, poderemos ter mais segurança em inferir os mecanismos que de fato estão ocasionando a diminuição na biodiversidade, facilitando o planejamento de medidas para evitá-los. 


\section{CONCLUSÃO}

Pressão de propágulos e distúrbios associados à perda de habitat são igualmente importantes como determinantes da invasão de remanescentes florestais por cachorros, apresentando efeito aditivo e não sinérgico. É possível que a ausência de sinergia entre estes, sabidamente importantes, determinantes de invasões biológicas esteja relacionada aos subsídios recebidos da população humana, pois cachorros não dependem dos recursos propiciados por distúrbios para sobreviver. A densidade de cachorros parece ser um aspecto da pressão de propágulos mais importante do que a distribuição espacial dos indivíduos, indicando que, em uma população maior, também é maior a probabilidade de encontrarmos indivíduos com características que facilitem a invasão. Porém, é possível que a distribuição espacial de propágulos seja mais importante na invasão por espécies não subsidiadas, que realizam deslocamentos menores, ou tenham menor poder de dispersão, do que os cachorros. Além disso, a cobertura florestal, especialmente a cobertura florestal total (florestas nativas e exóticas), é mais importante que a extensão de bordas para a intensidade de invasão, indicando que o mecanismo mediando a invasão neste caso é a quantidade de barreiras aos movimentos dos cachorros (cobertura florestal) e não a quantidade de pontos de acesso aos remanescentes florestais (extensão de bordas). Temperaturas mais amenas aumentam a chance de detectar que sítios amostrais estão ocupados por cachorros, indicando que temperaturas altas diminuem a atividade e movimentação destes animais, o que deve ser levado em conta no planejamento de estudos futuros.

A grande densidade de cachorros criados e o desmatamento ocasionam em nossa região de estudo, e provavelmente em muitas paisagens rurais similares, um número e proporção de cachorros invasores expressivos, colocando a espécie como a mais abundante entre os carnívoros nas florestas remanescentes. Isso somado aos vários efeitos negativos dos cachorros sobre a fauna silvestre (efeitos letais e não letais da predação, competição e transmissão de doenças) e sobre o homem (transmissão de zoonoses) sugere a necessidade urgente de ações que visem controlar essas invasões. Essas ações devem levar em conta a estrutura da paisagem e ser prioritariamente implantadas em paisagens mais desmatadas, que, além de concentrarem as maiores ameaças à biodiversidade, sofrem com maior intensidade de invasão. Como medidas para controlar a invasão de cachorros, sugerimos, além dos tradicionais métodos de controle populacional (forma de combater a pressão de propágulos), a valorização da manutenção e restauração de florestas nativas, assim como o manejo da distribuição espacial, especialmente de florestas plantadas (e.g. eucaliptos), como forma de dificultar a movimentação de cachorros em áreas de maior interesse. 
Por fim, destacamos que o entendimento atual dos mecanismos causais relacionados à perda de biodiversidade, especialmente no caso da fauna de mamíferos de maior porte, podem estar equivocados, dado que a invasão por cachorros está associada às duas ameaças principais a estes animais hoje reconhecidas: a perda de habitat, e a densidade populacional humana relacionada à caça. 


\section{REFERÊNCIAS BIBLIOGRÁFICAS}

Baillie, J.E.M., Hilton-Taylor, C., Stuart, S.N. (Editores). 2004. 2004 IUCN Red List of Threatened Species. A Global Species Assessment. IUCN, Gland, Switzerland and Cambridge, UK.

Banks-Leite, C., Ewers, R.M., Metzger, J.P. 2012. Unraveling the drivers of community dissimilarity and species extinction in fragmented landscapes. Ecology 93: 2560-2569

Bellard, C., Cassey, P., Blackburn, T.M. 2016a. Alien species as a driver of recent extinctions. Biology Letters 12: 20150623

Bellard, C., Genovesi, P., Jeschke, J.M. 2016b. Global patterns in threats to vertebrates by biological invasions. Proceedings of the Royal Society B 283: 20152454

Berman, M., Dunbar, I. 1983. The social behavior of free ranging suburban dogs. Applied Animal Ethology 10: 5-17

Blackburn, T.M., Lockwood, J.L., Cassey, P. 2015. The influence of numbers on invasion success. Molecular Ecology 24: 1942-1953

Blackburn, T.M., Prowse, T.A.A., Lockwood, J.L., Cassey, P. 2013. Propagule pressure as a driver of establishment success in deliberately introduced exotic species: fact or artefact? Biological Invasions 15: 1459-1469

Bossenbroek, J.M. Kraft, C.E., Nekola, J.C. 2001. Prediction of long-distance dispersal using gravity models: Zebra mussel invasion of inland lakes. Ecological Applications 11: 1778-1788

Britton-Simmons, K.H., Abbott, K.C. 2008. Short- and long-term effects of disturbance and propagule pressure on a biological invasion. Journal of Ecology 96: 68-77

Brook B.W., Sodhi N.S., Bradshaw C.J.A. 2008. Synergies among extinction drivers under global change. Trends in Ecology \& Evolution 23: 453-460

Burnham, K.P., Anderson, D.R. 2002. Model selection and multimodel inference: a practical information-theoretic approach. 2da ed. Springer, New York

Butler, J.R.A., du Toit, J.T. 2002. Diet of free-ranging domestic dogs (Canis familiaris) in rural Zimbabwe: implications for wild scavengers on the periphery of wildlife reserves. Animal Conservation 5: 29-37

Butler, J.R.A., du Toit, J.T., Bingham, J. 2004. Free-ranging domestic dogs (Canis familiaris) as predators and prey in rural Zimbabwe: threats of competition and disease to large wild carnivores. Biological Conservation 115: 369:378 
Byers, J.E. 2002.Impact of non-indigenous species on natives enhanced by anthropogenic alteration of selection regimes. Oikos 97: 449-458

Campos, C.B., Esteves, C.F., Ferraz, K.M.P.M.B., Crawshaw, P.G., Verdade, L.M., 2007. Diet of freeranging cats and dogs in a suburban and rural environment, south-eastern Brazil. Journal of Zoology 273: 14-20

Cassano, C.R., Barlow, J., Pardini, R. 2014. Forest loss or management intensification? Identifying causes of mammal decline in cacao agroforests. Biological Conservation 169: 14-22

Catford, J.A., Jansson, R., Nilsson, C. 2009. Reducing redundancy in invasion ecology by integrating hypotheses into a single theoretical framework. Diversity and Distributions 15: 22-40

Chiarello, A.G. 1999. Effects of fragmentation of the Atlantic forest on mammal communities in south-eastern Brazil. Biological Conservation 89: 71-82

Clark, G.F., Johnston, E.L. 2009. Propagule pressure and disturbance interact to overcome biotic resistance of marine invertebrate communities. Oikos 118: 1679-1686

Clavero, M., García-Berthou, E. 2005. Invasive species are a leading cause of animal extinctions. Trends in Ecology \& Evolution 20: 110

Cleaveland, S., Appel, M.G.J., Chalmers, W.S.K., Chillingworth, C., Kaare, M., Dye, C. 2000. Serological and demographic evidence for domestic dogs as a source of canine distemper virus infection for Serengeti wildlife. Veterinary Microbiology 72: 217-227

Colautti, Robert I., Grigorovich, I.A., Maclsaac, H.J. 2006. Propagule pressure: A null model for biological invasions. Biological Invasions 8: 1023:1037

Crooks, J.A., Chang, A.L., Ruiz, G.M. 2011. Aquatic pollution increases the relative success of invasive species. Biological Invasions 13: 165-176

Cullen, L., Bodmer, R.E., Padua, C.V. 2000. Effects of hunting in habitat fragments of the Atlantic forests, Brazil. Biological Conservation 95: 49-56

Curi, N.H.A., Paschoal, A.M.O., Massara, R.L., Marcelino, A.P., Ribeiro, A.A., et al. 2014. Factors associated with the seroprevalence of leishmaniasis in dogs living around Atlantic Forest fragments. Plos One 9: e104003.

D'Antonio, C.M. Dudley, T.L. \& Mack, M.C. 1999. Disturbance and biological invasions: direct effects and feedbacks. pp. 413-452. Walker, L.R. (Editor). Ecosystems of disturbed ground. Elsevier, New York. 
Davis, M.A., Grime, P., Thompson, K. 2000. Fluctuating resources in plant communities: a general theory of invasibility. Journal of Ecolgy 88: 528: 534

Didham, R.K., Tylianakis, J.M., Gemmell, N.J., Rand, T.A., Ewers, R.M. 2007. Interactive effects of habitat modification and species invasion on native species decline. Trends in Ecology \& Evolution 22: 489-496

Eschtruth, A.K., Battles, J.J. 2009. Assessing the relative importance of disturbance, herbivory, diversity, and propagule pressure in exotic plant invasion. Ecological Monographs 79: 265280

Estavillo, C., Pardini, R., Rocha, P.L.B. 2013. Forest Loss and the biodiversity threshold: an evaluation considering species habitat requirements and the use of matrix habitats. Plos one 8: e82369

Ewers, R.M., Didham, R.K. 2006. Confounding factors in the detection of species responses to habitat fragmentation. Biological Reviews 81: 117-142

Fahrig, L. 2003. Effects of habitat fragmentation on biodiversity. Annual Review of Ecology Evolution and Systematics 34: 487-515

Farris, Z.J., Golden, C.D., Karpanty, S., Murphy, A., Stauffer, D., et al. 2015. Hunting, exotic carnivores, and habitat loss: anthropogenic effects on a native carnivore community, Madagascar. Plos One 10: e0136456

Foley J.A., DeFries R., Asner G.P., Barford C., Bonan G., et al. 2005. Global consequences of land use. Science 309: 570-574

Fortes. F.S., Biondo, A.W., Molento, M.B. 2011. Brazilian spotted fever in dogs. Semina: Ciências Agrárias 32: 339-354

Frigeri, E., Cassano, C.R., Pardini, R. 2014. Domestic dog invasion in an agroforestry mosaic in southern Bahia, Brazil. Tropical Conservation Science 7: 508-528

Gantchoff, M.G., Belant, J.L. 2015. Anthropogenic and environmental effects on invasive mammal distribution in northern Patagonia, Argentina. Mammalian Biology 80: 54-58

Gerber, B.D., Karpanty, S.M., Kelly, M.J. 2012. Evaluating the potential biases in carnivore capturerecapture studies associated with the use of lure and varying density estimation techniques using photographic-sampling data of the Malagasy civet. Population Ecology 54: 43-54

Gingold, G., Yom-Tov, Y., Kronfeld-Schor, N., Geffen, E. 2009. Effect of guard dogs on the behavior and reproduction of gazelles in cattle enclosures on the Golan Heights. Animal Conservation 12: $155-162$ 
Gompper, M.E. 2014. The dog-human-wildlife interface: assessing the scope of the problem. Gompper, M.E. (Editor). Free-ranging gogs and wildlife conservation. Oxford University Press, Oxford

Gompper, M.E., Vanak, A.T. 2008. Subsidized predators, landscapes of fear and disarticulated carnivore communities. Animal Conservation 11: 13-14

Gonzáles-Moreno, P., Diez, J.M., Ibáñez, I., Font, X., Vilà, M. 2014. Plant invasions are contextdependent: multiscale effects of climate, human activity and habitat. Diversity and Distributions 20: 720-731

Gonzáles-Moreno, P., Pino, J., Carreras, D., Basnou, C., Fernández-Rebollar, I., Vilà, M. 2013. Quantifying the landscape influence on plant invasions in Mediterranean coastal habitats. Landscape Ecology 28: 891-903

González-Suárez, M., Revilla, E. 2014. Generalized drivers in the mammalian endangerment process. Plos One 9: e90292

Heger, T., Saul, W.C., Trepl, L. 2013.What biological invasions 'are' is a matter of perspective. Journal for Nature Conservation 21: 93-96

Hufbauer, R.A., Rutschmann, A., Serrate, B., Conchard, H.V., Facon, B. 2013. Journal of Evolutionary Biology 26: 1691-1699

Hughes, J., Macdonald, D.W. 2013. A review of the interactions between free-roaming domestic dogs and wildlife. Biological Conservation 157: 341-351

Hulme, P.E. 2009. Trade, transport and trouble: managing invasive species pathways in an era of globalization. Journal of Applied Ecology 46: 10-18

Jauni, M., Gripenberg, S., Ramula, S. 2015. Non-native plant species benefit from disturbance: a meta-analysis. Oikos 124: 122-129

Joseph, L.N., Elkin, C., Martin, T.G., Possingham, H.P. 2009. Modeling abundance using N-mixture models: the importance of considering ecological mechanisms. Ecological Applications 19: 631-642

Kéry, M., Royle, J. A., Schmid, H. 2005. Modeling avian abundance from replicated counts using binomial mixture models. Ecological Applications 15: 1450-1461

Kolar, C.S., Lodge, D.M. 2001. Progress in invasion biology: predicting invaders. Trends in Ecology \& Evolution 16: 199-204 
Lacerda, A.C.R., Tomas, W.M., Marinho-Filho, J. 2009. Domestic dogs as an edge effect in the Brasília National Park, Brazil: interactions with native mammals. Animal Conservation 12: 477-487

Lockwood, J.L., Cassey, P., Blackburn, T. 2005. The role of propagule pressure in explaining species invasions. Trends in Ecology \& Evolution 20: 223-228

Lowry, E., Rollinson, E.J., Laybourn, A.J., Scott, T.E., Aiello-Lammens, M.E., et al. 2013. Biological invasions: a field synopsis, systematic review, and database of the literature. Ecology and Evolution 3: 182-196

MacKenzie, D.I., Nichols, J.D., Lachman, G.B., Droege, S., Royle, J. A., Langtimm, C.A. 2002. Estimating site occupancy rates when detection probabilities are less than one. Ecology 83: 2248-2255

Macpherson, C.N.L. 2005. Human behaviour and the epidemiology of parasitic zoonoses. International Journal for Parasitology 35: 1319-1331

Manor, R., Saltz, D. 2004. The impact of free-roaming dogs on gazelle kid/female ratio in a fragmented area. Biological Conservation 119: 231-236

Maron, J.L., Waller, L.P., Hahn, M.A., Diaconu, A., Pal, R.W. et al. 2013. Effects of soil fungi, disturbance and propagule pressure on exotic plant recruitment and establishment at home and abroad. Journal of Ecology 101: 924-932

Meek, P.D. 1999. The movement, roaming behaviour and home range of free-roaming domestic dogs, Canis lupus familiaris, in coastal New South Wales. Wildlife Research 26: 847-855

Murphy G.E.P., Romanuk T.N. 2014. A meta-analysis of declines in local species richness from human disturbances. Ecology and Evolution 4: 91-103

Newsome, T.M., Dellinger, J.A., Pavey, C.R., Ripple, W.J., Shores, C.R. et al. 2015. The ecological effects of providing resource subsidies to predators. Global Ecology and Biogeography 24: 111

Olden, J.D, Poff, N.L., Douglas, M.R., Douglas, M.E., Fausch, K.D. 2004. Ecological and evolutionary consequences of biotic homogenization. Trends in Ecology \& Evolution 19: 18-24

Pang, J.F., Kluetsch, C., Zou, X.J., Zhang, A.B., Luo, L.Y. et al. 2009. mtDNA data indicate a single origin for dogs south of Yangtze river, less than 16,300 years ago, from numerous wolves. Molecular Biology and Evolution 26: 2849-2864 
Pardini, R., Bueno, A.A., Gardner, T.A., Prado, P.I., Metzger, J.P. 2010. Beyond the fragmentation threshold hypothesis: regime shifts in biodiversity across fragmented landscapes. Plos One 5: e13666

Pasher, J., Mitchell, S.W., King, D.J., Fahrig, L., Smith, A.C., Lindsay, K.E. 2013. Optimizing landscape selection for estimating relative effects of landscape variables on ecological responses. Landscape Ecology 28:371-383

Pejchar, L., Mooney, H.A. 2009. Invasive species, ecosystem services and human well-being. Trends in Ecology \& Evolution 24: 497 - 504

Preisser, E.L., Bolnick, D.I., Benard, M.F. 2005. Scared to death? The effects of intimidation and consumption in predator-prey interactions. Ecology 86: 501-509

Pulliam, H.R. 1988. Sources, sinks, and population regulation. American Naturalist 132: 652-661

Ribeiro, M.C., Metzger, J.P., Martensen, A.C., Ponzoni, F.J., Hirota, M.M. 2009. The Brazilian Atlantic Forest: How much is left, and how is the remaining forest distributed? Implications for conservation. Biological Conservation 142: 1141:1153

Ricketts, T.H. 2001. The matrix matters: effective isolation in fragmented landscapes. American Naturalist 158: 87-99

Ries, L., Fletcher, R.J., Battin, J., Sisk, T.D. 2004. Ecological responses to habitat edges: mechanisms, models, and variability explained. Annual Review of Ecology Evolution and Systematics 35: 491-522

Royle, J.A. 2004. N-mixture models for esttimating population size from spatially replicates counts. Biometrics 60: 108-115

Ruiz-Izaguirre, E., van Woersem, A., Eilers, K.H.A.M., van Wieren, S.E., Bosch, G. et al. 2015. Roaming characteristics and feeding practices of village dogs scavenging sea-turtle nests. Animal Conservation 18: 146-156

Sakai, A.K., Allendorf, F.W., Holt, J.S., Lodge, D.M., Molofsky, J., et al. 2001. The population biology of invasive species. Annual Review of Ecology and Systematics 32: 305-332

Sepulveda, M., Pelican, K., Cross, P., Eguren, A., Singer, R. 2015. Fine-scale movements of rural free-ranging dogs in conservation areas in the temperate rainforest of the coastal range of southern Chile. Mammalian Biology 80: 290-297

Shea, K., Chesson, P. 2002. Community ecology theory as a framework for biological invasions. Trends in Ecology \& Evolution 17: 170-176 
Sheriff, M.J., Krebs, C.J., Boonstra, R. 2009. The sensitive hare: sublethal effects of predator stress on reproduction in snowshoe hares. Journal of Animal Ecology 78: 1249-1258

Silva-Rodríguez, E.A., Sieving, K.E. 2012. Domestic dogs shape the landscape-scale distribution of a threatened forest ungulate. Biological Conservation 150: 103-110

Simberloff, D. 2009. The role of propagule pressure in biological invasions. Annual Review of Ecology Evolution and Systematics 40: 81-102

Simon, K.S., Townsend, C.R. 2003. Impacts of freshwater invaders at different levels of ecological organisation, with emphasis on salmonids and ecosystem consequences. Freshwater Biology 48: 982-994

Sparkes, J., Körtner, G., Ballard, G., Fleming, P.J.S., Brown, W.Y. 2014. Effects of Sex and Reproductive State on Interactions between Free-Roaming Domestic Dogs. Plos One 9: e116053

Srbek-Araujo, A. C.; Chiarello, A. G. 2008. Domestic dogs in Atlantic forest preserves of southeastern Brazil: a camera-trapping study on patterns of entrance and site occupancy rates. Brazilian Journal of Biology 68: 771-779

Strayer, L.S. 2012. Eight questions about invasions and ecosystem functioning. Ecology Letters 15: $1199-1210$

Thomas, S.M., Moloney, K.A. 2015. Combining the effects of surrounding land-use and propagule pressure to predict the distribution of an invasive plant. Biological Invasions 17: 477-495

Thomson, D.M., 2007. Do source-sink dynamics promote the spread of an invasive grass into a novel habitat? Ecology 88: 3126-3134

Tscharntke, T., Tylianakis, J.M., Rand, T.A., Didham, R.K., Fahrig, L., et al. 2012. Landscape moderation of biodiversity patterns and processes - eight hypotheses. Biological Reviews 87: $661-685$

Umetsu, F., Metzger, J.P., Pardini, R. 2008. Importance of estimating matrix quality for modeling species distribution in complex tropical landscapes: a test with Atlantic forest small mammals. Ecography 31: 359-370

Umetsu, F., Pardini, R. 2007. Small mammals in a mosaic of forest remnants and anthropogenic habitats-evaluating matrix quality in an Atlantic forest landscape. Landscape Ecology 22: $517: 530$

van Bommel, L., Johnson, C.N. 2014. Where do livestock guardian dogs go? Movement patterns of free-ranging Maremma sheepdogs. Plos One 9: e111444 
Vanak, A.T., Gompper, M.E. 2009. Dogs Canis familiaris as carnivores: their role and function inintraguild competition. Mammal Review 39: 265-283

Vanak, A.T., Gompper, M.E. 2010. Interference competition at the landscape level: the effect of free-ranging dogs on a native mesocarnivore. Journal of Applied Ecology 47: 1225-1232

Vilà, M., Ibáñez, I. 2011. Plant invasions in the landscape. Landscape Ecology 26: 461-472

vonHoldt, B.M., Pollinger, J.P., Lohmueller, K.E., Han, E., Parker, H.G. et al. 2010. Genome-wide SNP and haplotype analyses reveal a rich history underlying dog domestication. Nature 464: 898-903

Warren II, R.J., Bahn, V., Bradford, M.A. 2012. The interaction between propagule pressure, habitat suitability and density-dependent reproduction in species invasion. Oikos 121: 874881

Woodroffe, R., Ginsberg, J.R. 1999. Conserving the African wild dog Lycaon pictus. I. Diagnosing and treating causes of decline. Oryx 33: 132-142

Young, J.K., Olson, K.A., Reading, R.P., Amgalanbaatar, S., Berger, J. 2011. Is wildlife going to the dogs? Impacts of feral and free-roaming dogs on wildlife populations. Bioscience 61: 125132

Zapata-Ríos, G., Branch, L.C. 2016. Altered activity patterns and reduced abundance of native mammals in sites with feral dogs in the high Andes. Biological Conservation 193: 9-16 


\section{ANEXOS}

Anexo 1
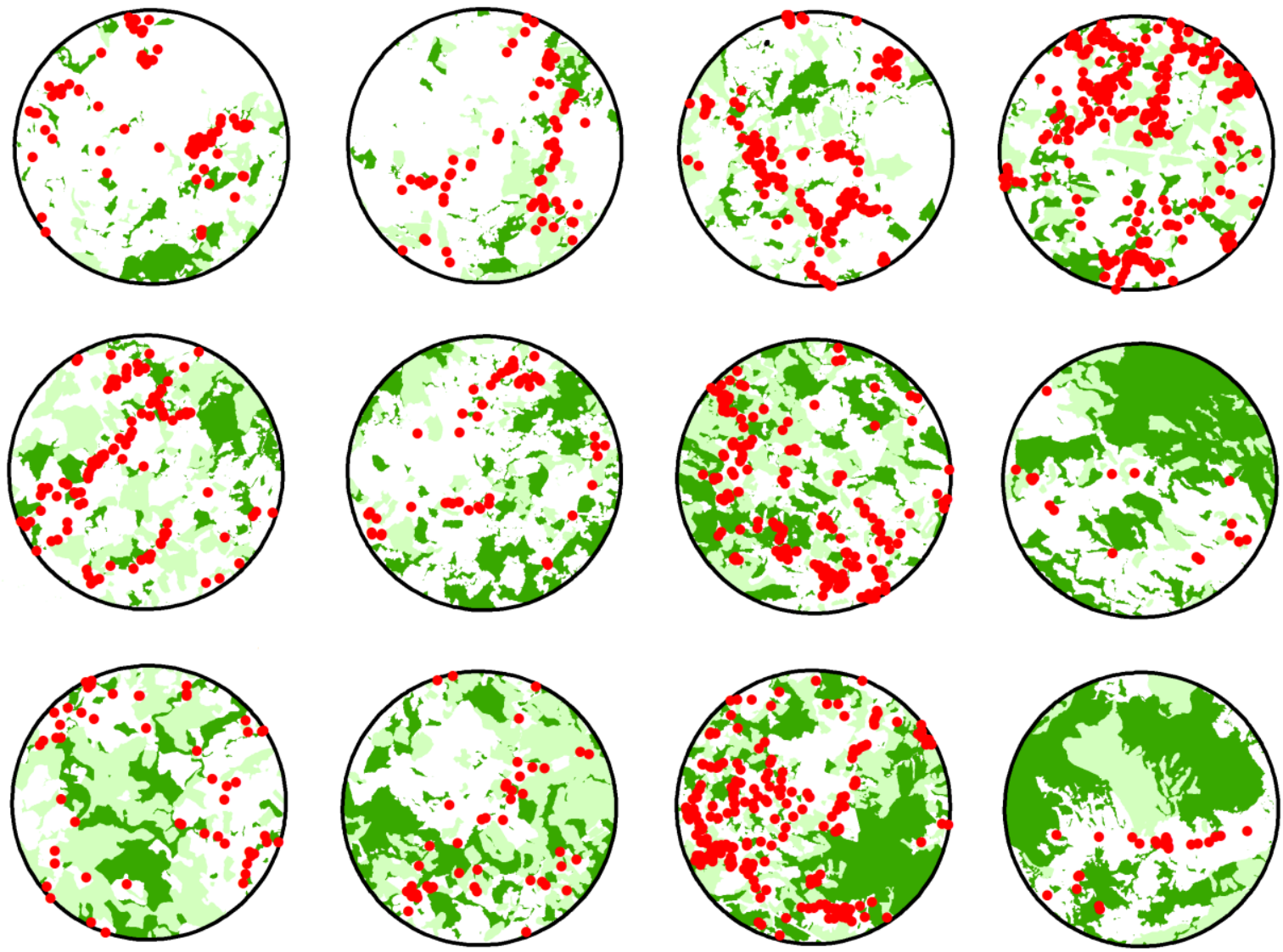

Figura S1: Uso do solo e distribuição dos domicílios (pontos vermelhos) onde são criados cachorros em cada uma das 12 paisagens de estudo. Verde escuro: remanescentes de florestas nativas; verde claro: plantações de eucalipto; branco: áreas alteradas abertas. 


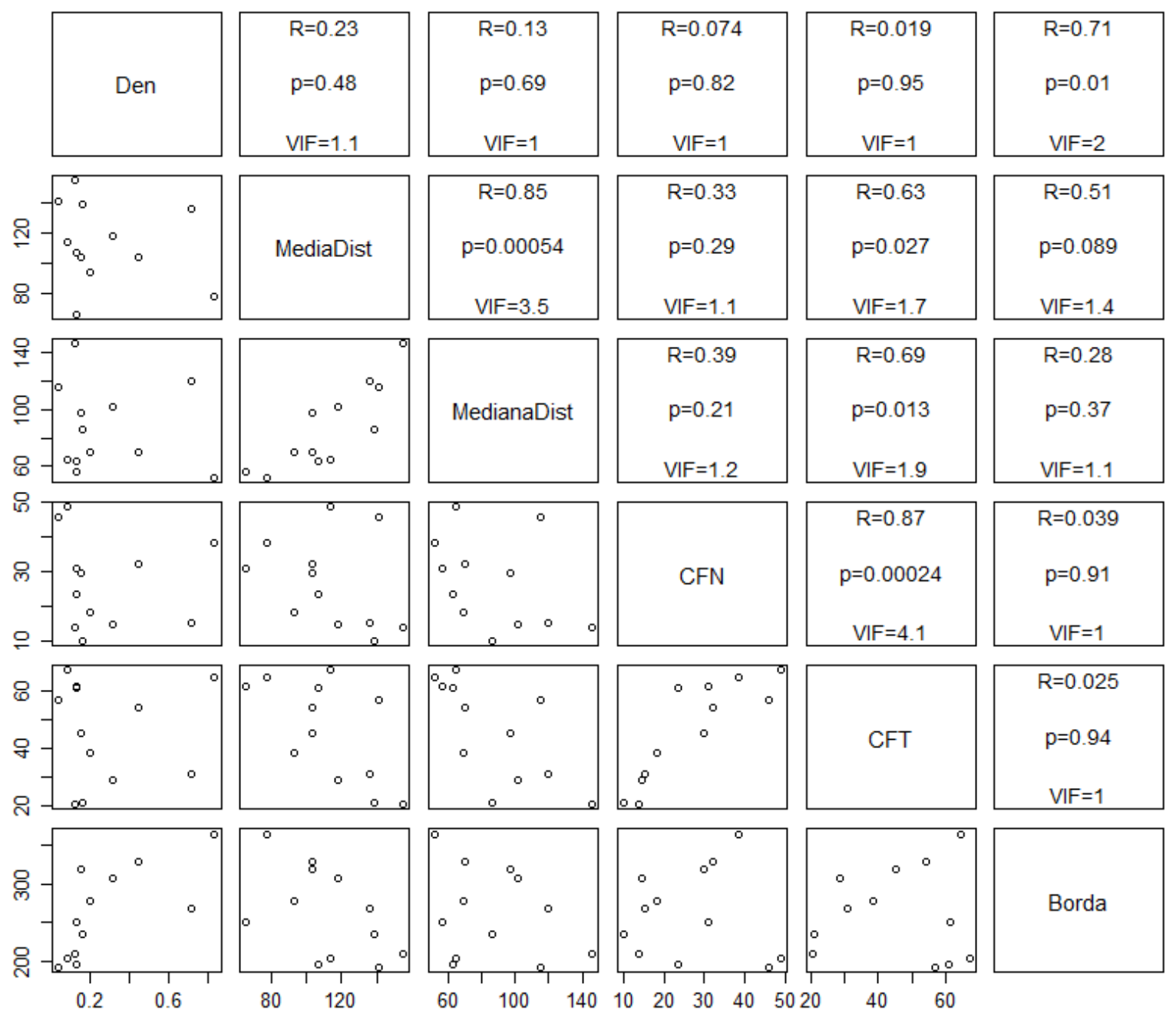

Figura S2: Gráficos de correlação (inferior) e valores de correlação de Pearson ( $r$ e p) e graus de colinearidade (VIF) (superior) entre as variáveis de pressão de propágulos e aquelas de distúrbios associados à perda de habitat entre as 12 paisagens de estudo. Den: densidade de cachorros criados, MediaDist: média das distâncias entre os locais de criação dos cachorros e o fragmento de floresta nativo mais próximo, MedianaDist: mediana das distâncias entre os locais de criação dos cachorros e o fragmento de floresta nativo mais próximo; CFT: cobertura florestal total, CFN: cobertura florestal nativa, Borda: extensão de borda entre florestas nativas e áreas abertas. 


\section{Anexo 3: Explicação da escolha do tipo de distribuição de abundância utilizada nos modelos}

Para definir qual tipo de distribuição de abundância utilizaríamos (Poisson, binomial negativa ou Poisson inflacionada de zeros), primeiro rodamos o conjunto de modelos candidatos descritos no texto principal para as três distribuições, com a detectabilidade modelada como uma função aditiva do esforço e época de amostragem. Por AICc, selecionamos os modelos melhor ranqueados em cada distribuição. Posteriormente, testamos se as estimativas dos modelos eram estáveis, ou seja, se elas estabilizavam independente do valor de k (parâmetro da integração da distribuição) escolhido. O modelo de distribuição binomial negativa mostrou-se instável, com estimativas de abundância maiores conforme aumento de $k$, chegando a atingir valores biologicamente irreais e, portanto, a distribuição binomial negativa mostrou-se não adequada (Joseph et al., 2009) (Tabela S1). Para as demais duas distribuições, testamos a qualidade do ajuste do modelo melhor ranqueado através de um bootstrap paramétrico com 10000 reamostragens e a estatística qui-quadrado e os comparamos através do AICc (Kery et al., 2005). A distribuição Poisson mostrou-se a mais plausível (Tabela S2).

Tabela S1: Médias das estimativas de abundância de cachorros nos remanescentes florestais entre as paisagens estudadas a partir dos modelos melhor ranqueados para cada distribuição de abundância (Poi: Poisson; BN: binomial negativa; PIZ: Poisson inflacionada de zeros) em relação a diferentes valores de $k$ (parâmetro de integração da distribuição). Cobertura florestal total (CFT) e densidade de cachorros criados (Den). Em todos os modelos o parâmetro detectabilidade teve como covariáveis esforço amostral e época de amostragem p(esforço:época).

\begin{tabular}{lcccccccc}
\hline Modelos & \multicolumn{7}{c}{$\mathbf{k}$} \\
\cline { 2 - 8 } & $\mathbf{5 0}$ & $\mathbf{1 0 0}$ & $\mathbf{1 5 0}$ & $\mathbf{2 0 0}$ & $\mathbf{2 5 0}$ & $\mathbf{3 0 0}$ & $\mathbf{5 0 0}$ \\
Poi $: \lambda$ (CFT:Den) & 17.81 & 30.32 & 30.96 & 30.96 & 30.96 & 30.96 & 30.96 \\
PIZ $: \lambda$ (CFT:Den) & 17.88 & 29.04 & 29.06 & 29.06 & 29.06 & 29.06 & 29.06 \\
BN $: \lambda($ (.) & 20.3 & 36.3 & 51.45 & 66.12 & 80.46 & 94.52 & 148.91 \\
\hline
\end{tabular}


Tabela S2: Comparação dos modelos de abundância melhor ranqueados para as distribuições Poisson (Poi) e Poisson inflada de zeros (PIZ). Número de parâmetros estimados (K), critérios de informação de Akaike corrigidos para pequenas amostras (AICC), diferenças entre AICc dos modelos e daquele melhor ranqueado $(\triangle A I C C)$ e ajuste do modelo aos dados $(p)$. Cobertura florestal total (CFT) e densidade de cachorros criados (Dens). Em todos os modelos o parâmetro detectabilidade teve como covariáveis esforço amostral e época de amostragem p(esforço:época).

\begin{tabular}{cccccccc}
\hline & & \multicolumn{9}{c}{ Coeficientes } \\
Modelos & K & AICc & $\Delta$ AICc & $\omega i$ & Var1 (SE) & Var2 (SE) & Ajuste (p) \\
\hline Poi $: \lambda$ (CFT:Den) & 6 & 349.31 & 0 & $>0.99$ & $-0.0192(0.0048)$ & $1.8890(0.3483)$ & 0.21 \\
PIZ $: \lambda$ (CFT:Den) & 7 & 362.53 & 13.22 & $<0.01$ & $-0.0191(0.0049)$ & $1.8744(0.3518)$ & 0.21 \\
\hline
\end{tabular}




\section{Anexo 4: Estimativas de abundância variando-se o número e duração das sessões de amostragem}

Para testar se diferentes definições de sessões de amostragem poderiam ocasionar resultados discrepantes, rodamos os modelos candidatos descritos no texto principal para seis tipos de sessões (de 3, 4, 5, 6, 7 e 8 dias), usando a melhor distribuição de abundância (Poisson). Os resultados são qualitativamente similares (Tabelas S3), com os modelos considerados mais plausíveis que o nulo contendo, em todos os casos, uma variável de cobertura florestal ou a variável de densidade de cachorros criados ou ambas. O efeito de uma dada variável é qualitativamente o mesmo (positivo ou negativo) em todos os diferentes tipos de sessões. Apenas em uma situação, sessão de 3 dias, um modelo com uma variável diferente (mediana da distância entre o local de criação ao fragmento de floresta nativo mais próximo) foi considerado mais plausível que o nulo. As estimativas do melhor modelo de abundância de cachorros nas matas das 12 paisagens para todos os tipos de sessões testadas também são semelhantes (Figura S3).

Tabelas S3: Resultados da seleção de modelos da abundância de cachorros nos remanescentes florestais em função de variáveis de pressão de propágulo e de distúrbios associados à perda de habitat, utilizando a distribuição de Poisson e sessões de amostragem de 3 a 8 dias. Em todos os modelos o parâmetro detectabilidade teve como covariáveis esforço amostral e época de amostragem p(esforço:época). São mostrados os modelos melhor ranqueados que o modelo nulo e seus respectivos número de parâmetros estimados (K), critério de informação de Akaike corrigido para pequenas amostras (AICc), diferença entre AICc dos modelos e o AICc do modelo melhor ranqueado $(\triangle \mathrm{AICC})$ e peso de evidência ( $\omega \mathrm{i})$. Den: densidade de cachorros criados, MedianaDist: mediana das distâncias entre os locais de criação dos cachorros e o fragmento de floresta nativo mais próximo, CFT: cobertura florestal total, CFN: cobertura florestal nativa.

\begin{tabular}{|c|c|c|c|c|c|c|c|c|}
\hline $\begin{array}{c}\text { Dias por } \\
\text { sessão }\end{array}$ & Modelos & K & AlCc & $\Delta \mathrm{AICc}$ & $\omega \mathbf{i}$ & Var1 (SE) & $\begin{array}{c}\text { Coeficientes } \\
\text { Var2 (SE) }\end{array}$ & Interação (SE) \\
\hline \multirow{9}{*}{3} & $\lambda$ (CFT:Den) & 6 & 632.72 & 0 & 0.87 & $-0.0175(0.0044)$ & $1.7140(0.3127)$ & - \\
\hline & $\lambda$ (CFN:Den) & 6 & 637.82 & 5.09 & 0.07 & $-0.0202(0.0064)$ & $1.5906(0.3124)$ & - \\
\hline & $\lambda$ (Den) & 5 & 638.17 & 5.45 & 0.06 & $1.5518(0.3131)$ & - & - \\
\hline & $\lambda\left(\mathrm{CFT}^{*}\right.$ Den $)$ & 7 & 645.7 & 12.98 & 0 & $-0.0203(0.0072)$ & $1.2956(0.9237)$ & $0.0077(0.0160)$ \\
\hline & $\lambda(\mathrm{CFT})$ & 5 & 648.39 & 15.67 & 0 & $-0.0169(0.0051)$ & - & - \\
\hline & $\lambda($ MedianaDist) & 5 & 649.4 & 16.68 & 0 & $0.0100(0.0032)$ & - & - \\
\hline & $\lambda(\mathrm{CFN})$ & 5 & 650.04 & 17.32 & 0 & $-0.0212(0.0071)$ & - & - \\
\hline & $\lambda\left(\right.$ CFN*Den $^{*}$ & 7 & 650.93 & 18.21 & 0 & $-0.0179(0.0103)$ & $1.8138(0.8324)$ & $-0.0067(0.0233)$ \\
\hline & $\lambda()$. & 4 & 652.41 & 19.68 & 0 & & - & - \\
\hline \multirow{2}{*}{4} & $\lambda$ (CFT:Den) & 6 & 498.12 & 0 & 0.7 & $-0.0169(0.0044)$ & $1.6994(0.3060)$ & - \\
\hline & $\lambda$ (Den) & 5 & 501.02 & 2.9 & 0.17 & $1.5420(0.3212)$ & - & - \\
\hline
\end{tabular}




\begin{tabular}{|c|c|c|c|c|c|c|c|c|}
\hline & $\lambda$ (CFN:Den) & 6 & 501.54 & 3.41 & 0.13 & $-0.0200(0.0066)$ & $1.5727(0.3158)$ & - \\
\hline & $\lambda(\mathrm{CFT})$ & 5 & 510.82 & 12.7 & 0 & $-0.0163(0.0055)$ & - & - \\
\hline & $\lambda\left(\mathrm{CFT}^{*}\right.$ Den $)$ & 7 & 510.83 & 12.7 & 0 & $-0.0210(0.0107)$ & $1.4678(0.8571)$ & $0.0032(0.0243)$ \\
\hline & $\lambda(\mathrm{CFN})$ & 5 & 511.09 & 12.97 & 0 & $-0.0219(0.0076)$ & - & - \\
\hline & $\lambda()$. & 4 & 512.76 & 14.64 & 0 & & - & - \\
\hline \multirow{7}{*}{5} & $\lambda($ CFT:Den) & 6 & 421.5 & 0 & 0.62 & $-0.0152(0.0045)$ & $1.5748(0.3129)$ & - \\
\hline & $\lambda($ Den $)$ & 5 & 423.19 & 1.69 & 0.27 & $1.4615(0.3178)$ & - & - \\
\hline & $\lambda($ CFN:Den) & 6 & 425.01 & 3.52 & 0.11 & $-0.0178(0.0064)$ & $1.4665(0.3144)$ & - \\
\hline & $\lambda(\mathrm{CFT})$ & 5 & 432.5 & 11 & 0 & $-0.0152(0.0052)$ & - & - \\
\hline & $\lambda(\mathrm{CFN})$ & 5 & 433.19 & 11.69 & 0 & $-0.0199(0.0072)$ & - & - \\
\hline & $\lambda\left(\right.$ CFT $^{*}$ Den $)$ & 7 & 433.49 & 12 & 0 & $-0.0219(0.0103)$ & $1.0631(0.8687)$ & $0.0121(0.0242)$ \\
\hline & $\lambda()$. & 4 & 434.23 & 12.73 & 0 & & - & - \\
\hline \multirow{8}{*}{6} & $\lambda($ CFT:Den) & 6 & 349.31 & 0 & 0.82 & $-0.0192(0.0048)$ & $1.8890(0.3483)$ & - \\
\hline & $\lambda($ CFN:Den) & 6 & 353.71 & 4.39 & 0.09 & $-0.0230(0.0073)$ & $1.7437(0.3566)$ & - \\
\hline & $\lambda($ Den) & 5 & 353.77 & 4.45 & 0.09 & $1.6553(0.3520)$ & - & - \\
\hline & $\lambda\left(\right.$ CFT $^{*}$ Den $)$ & 7 & 362.48 & 13.16 & 0 & $-0.0205(0.0080)$ & $1.6900(1.0779)$ & $0.0036(0.0184)$ \\
\hline & $\lambda(\mathrm{CFT})$ & 5 & 363.24 & 13.92 & 0 & $-0.0177(0.0056)$ & - & - \\
\hline & $\lambda(\mathrm{CFN})$ & 5 & 364.26 & 14.94 & 0 & $-0.0231(0.0079)$ & - & - \\
\hline & $\lambda$ (MedianaDist) & 5 & 365.56 & 16.25 & 0 & $0.0094(0.0035)$ & - & - \\
\hline & $\lambda()$. & 4 & 366.23 & 16.91 & 0 & - & - & - \\
\hline \multirow{8}{*}{7} & $\lambda($ CFT:Den) & 6 & 338.45 & 0 & 0.75 & $-0.0162(0.0045)$ & $1.8219(0.3193)$ & - \\
\hline & $\lambda($ CFN:Den) & 6 & 341.59 & 3.14 & 0.16 & $-0.0196(0.0063)$ & $1.6963(0.3143)$ & - \\
\hline & $\lambda($ Den) & 5 & 342.7 & 4.24 & 0.09 & $1.6495(0.2960)$ & - & - \\
\hline & $\lambda\left(\right.$ CFT $^{*}$ Den $)$ & 7 & 351.44 & 12.99 & 0 & $-0.0197(0.0076)$ & $1.3642(0.9988)$ & $0.0084(0.0170)$ \\
\hline & $\lambda\left(\right.$ CFN*Den $^{*}$ & 7 & 354.79 & 16.34 & 0 & $-0.0195(0.0104)$ & $1.7014(0.8823)$ & $-0.0001(0.0242)$ \\
\hline & $\lambda(\mathrm{CFN})$ & 5 & 359.33 & 20.88 & 0 & $-0.0199(0.0065)$ & - & - \\
\hline & $\lambda(\mathrm{CFT})$ & 5 & 359.61 & 21.16 & 0 & $-0.0146(0.0048)$ & - & - \\
\hline & $\lambda()$. & 4 & 361.87 & 23.41 & 0 & - & - & - \\
\hline \multirow{5}{*}{8} & $\lambda($ CFT:Den) & 6 & 270.97 & 0 & 0.48 & $-0.0145(0.0047)$ & $1.8410(0.3321)$ & - \\
\hline & $\lambda($ Den $)$ & 5 & 271.47 & 0.49 & 0.38 & $1.6618(0.3231)$ & - & - \\
\hline & $\lambda($ CFN:Den) & 6 & 273.48 & 2.51 & 0.14 & $-0.0175(0.0066)$ & $1.7270(0.3263)$ & - \\
\hline & $\lambda($ CFT*Den $)$ & 7 & 283.35 & 12.38 & 0 & $-0.0203(0.0076)$ & $0.9017(1.0501)$ & $0.0165(0.0175)$ \\
\hline & $\lambda()$. & 4 & 286.03 & 15.06 & 0 & & - & - \\
\hline
\end{tabular}




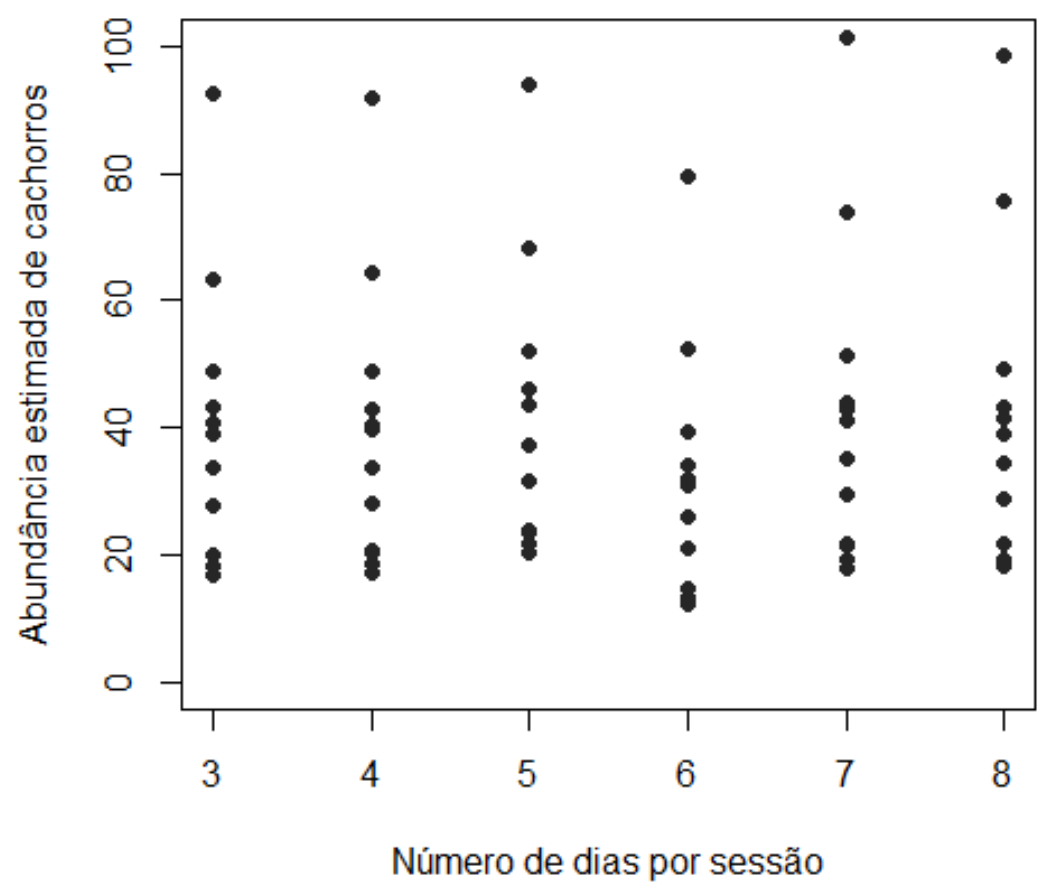

Figura S3: Estimativas da abundância de cachorros nos remanescentes florestais das 12 paisagens de estudo segundo o modelo melhor ranqueado para cada tipo de sessão de amostragem $(3,4,5$, 6,7 , e 8 dias). 